Une déclaration d'un comité consultatif (DCC) Comité consultatif national de l'immunisation $(\mathrm{CCNI})^{\dagger}$

\title{
DÉCLARATION SUR LA VACCINATION ANTIGRIPPALE POUR LA SAISON 2012-2013
}

\section{Préambule}

Le Comité consultatif national de l'immunisation (CCNI) donne à l'Agence de la santé publique du Canada des conseils constants et à jour liés à l'immunisation dans le domaine de la médecine, des sciences et de la santé publique. L'Agence de la santé publique du Canada reconnaît que les conseils et les recommandations figurant dans le présent document reposent sur les connaissances scientifiques les plus récentes et diffuse ce document à des fins d'information. Les personnes qui administrent le vaccin doivent également connaître le contenu du ou des monographies pertinentes sur le produit. Les recommandations du CCNI concernant l'utilisation et les autres renseignements qui figurent dans le présent document peuvent différer du contenu des monographies de produit. Les fabricants ont fait approuver les vaccins et ont démontré leur innocuité et leur efficacité uniquement lorsqu'ils sont utilisés conformément à la monographie de produit. Les membres du CCNI et les agents de liaison doivent se conformer à la politique de l'Agence de la santé publique du Canada régissant les conflits d'intérêts notamment déclarer chaque année les conflits d'intérêts possibles.

\section{Remarque IMPORTANTE au sujet des lignes directrices concernant les antiviraux :}

Les recommandations concernant les antiviraux ne relèvent plus du CCNI. Des lignes directrices sur I'utilisation des médicaments antiviraux destinées aux praticiens ont été publiées par l'Association pour la microbiologie médicale et l'infectiologie Canada (AMMI Canada); elles peuvent être consultées à l'adresse : http://www.ammi.ca/guidelines.

\footnotetext{
${ }^{\dagger}$ Membres du CCNI : Dre Bryna Warshawsky (Présidente), Dre Natasha Crowcroft, M ${ }^{m e}$ Anita Hanrahan, D ${ }^{r e}$ Bonnie Henry, D $D^{r e}$ Shainoor Ismail (Secrétaire exécutive), Dre Deepali Kumar, Dre Shelly McNeil, Dre Caroline Quach-Thanh, Dre Marina Salvadori, Dr Blair Seifert, Dre Nadine Sicard, Dre Wendy Vaudry, Dr Richard Warrington.
}

Représentants de liaison : Dr Jason Brophy (Association canadienne pour la recherche et l'évaluation en immunisation); Dr lan Gemmill (Association canadienne de santé publique); Dre Alison Mawle (Centers for Disease Control and Prevention des É.-U.); Dre Dorothy Moore (Société canadienne de pédiatrie); Dre Heather Morrison (Conseil des médecins hygiénistes en chef); Dre Anne Opavsky (Association pour la microbiologie médicale et l'infectiologie Canada); D' Pierre Plourde (Comité consultatif de la médecine tropicale et de la médecine des voyages); $D^{r e}$ Shelley Rechner (Collège des médecins de famille du Canada) et $D^{r e}$ Vyta Senikas (Société des obstétriciens et gynécologues du Canada)

Représentants d'office : Lt.-Col. Dr Jim Anderson (Forces canadiennes, Groupe des services liés à la santé, Ministère de la défense nationale); Dre Agnes Klein (Direction des produits biologiques et des thérapies génétiques, Santé Canada); Dre Barbara Law (Centre de l'immunisation et des maladies respiratoires infectieuses, Agence de la santé publique du Canada); Dr Marcus Lem (Direction générale de la santé des Premières nations et des Inuits, Santé Canada); M ${ }^{\text {me }}$ Danielle Poulin (Centre de l'immunisation et des maladies respiratoires infectieuses, Agence de la santé publique du Canada), Dre Joanne Xiong (Direction des produits biologiques et des thérapies génétiques, Santé Canada).

Membres du Groupe de travail sur l'influenza : Dre Brenda Cholin, Dr Curtis Cooper, Dr Scott Halperin, Dre Joanne Langley, Dre Allison McGeer, et Dr Paul Van Buynder. 


\section{Table des matières}

Sommaire de l'information contenue dans la présente déclaration
I. Introduction
II. Méthodes
III. Épidémiologie
IV. Vaccin antigrippal saisonnier
V. Recommandations
VI. Immunisation des travailleurs de la santé

Tableaux

Liste des abréviations

Références

Annexe 1 : Examen des nouvelles données : Enfants âgés de 24 à 59 mois 


\section{Sommaire de l'information contenue dans la présente déclaration}

Le tableau suivant résume l'information importante pour les vaccinateurs. Veuillez consulter le reste de la Déclaration pour obtenir plus de précisions.

\section{TABLEAU 1 : Sommaire de l'information contenue dans la présente déclaration du CCNI}

\section{\begin{tabular}{l|l} 
1. QUOI & Qu'est-ce que la grippe?
\end{tabular}}

La grippe est une infection respiratoire causée par les virus de l'influenza A et B. Au Canada, elle survient chaque année, généralement à la fin de l'automne et en hiver. Les symptômes comprennent généralement les suivants : apparition soudaine de maux de tête, frissons, toux, fièvre, perte d'appétit, douleurs musculaires et fatigue, écoulements nasaux, éternuements, larmoiements et irritation de la gorge. La grippe peut aussi provoquer des nausées, des vomissements et de la diarrhée, en particulier chez les enfants.

La plupart des gens se rétablissent de la grippe en l'espace de sept à dix jours, mais d'autres - dont les personnes âgées de 65 ans et plus et les adultes et enfants atteints d'une affection chronique - présentent un risque accru de complications graves telles que la pneumonie. Voir le site web de l'Agence de la santé publique du Canada pour des renseignements supplémentaires sur l'influenza (la grippe).

\section{En quoi consistent les vaccins antigrippaux?}

II y a actuellement huit vaccins trivalents contre l'influenza saisonnière homologués au Canada. Chaque province et chaque territoire informeront leur population au sujet des vaccins qui seront offerts dans le cadre de leur programme public de vaccination.

Sept des vaccins approuvés contre l'influenza saisonnière sont des vaccins trivalents inactivés (VTI), à virion fragmenté ou sous-unitaires. Cinq de ces vaccins (Agriflu ${ }^{\circledR}$, Fluviral $^{\circledR}$, Fluzone $^{\circledR}$, Influvac ${ }^{\circledR}$ et Vaxigrip ${ }^{\circledR}$ ) sont des produits classiques pour injection intramusculaire (IM) exempts d'adjuvant. Le sixième vaccin pour injection IM (Fluad ${ }^{\circledR}$ ) contient l'adjuvant MF59 et est destiné aux personnes de 65 ans et plus. Le septième VTI (IntanzaMD), approuvé pour les personnes de 18 ans et plus, est administré par voie intradermique. IntanzaMD est offert en deux préparations : $9 \mu \mathrm{g} / \mathrm{souche} \mathrm{pour} \mathrm{les}$ personnes de 18 à 59 ans et $15 \mu \mathrm{g} /$ souche pour les personnes de 60 ans et plus.

Le huitième produit antigrippal (FluMist ${ }^{\circledR}$ ) est un vaccin vivant atténué (VAI) approuvé pour les personnes de 2 à 59 ans. Les souches virales contenues dans FluMist ${ }^{\circledR}$ sont adaptées au froid et thermosensibles, ce qui fait qu'elles se répliquent dans le nasopharynx plutôt que dans les voies respiratoires inférieures; de plus, elles sont atténuées, de sorte qu'elles ne produisent pas de syndrome grippal classique.

Le vaccin antigrippal est sûr et bien toléré et il peut être administré dès l'âge de six mois (voir les indications et contre-indications selon l'âge propres à chaque produit).

- Les personnes présentant un risque élevé de complications liées à l'influenza - adultes et enfants atteints d'une affection chronique sous-jacente, notamment l'obésité morbide, résidents de maisons de soins infirmiers et d'autres établissements de soins de longue durée, personnes de 65 ans et plus, enfants de 6 à 59 mois, femmes enceintes et Autochtones.

- Les personnes qui pourraient transmettre la grippe à des sujets à risque élevé de complications - dispensateurs de soins de santé dans des établissements et en milieux communautaires, contacts familiaux de personnes à risque élevé, notamment des nourrissons de moins de 6 mois, personnes qui prennent soin d'enfants de moins de 59 mois et personnes qui fournissent des services à des sujets à risque élevé dans un milieu fermé (p. ex. équipage de navire).

- Les personnes qui fournissent des services communautaires essentiels.

Le CCNI encourage également tous les Canadiens à se faire vacciner, car la grippe peut aussi frapper des personnes qui ne sont pas considérées comme présentant un risque élevé de complications, ce qui se traduit par une morbidité et des coûts sociétaux importants. 


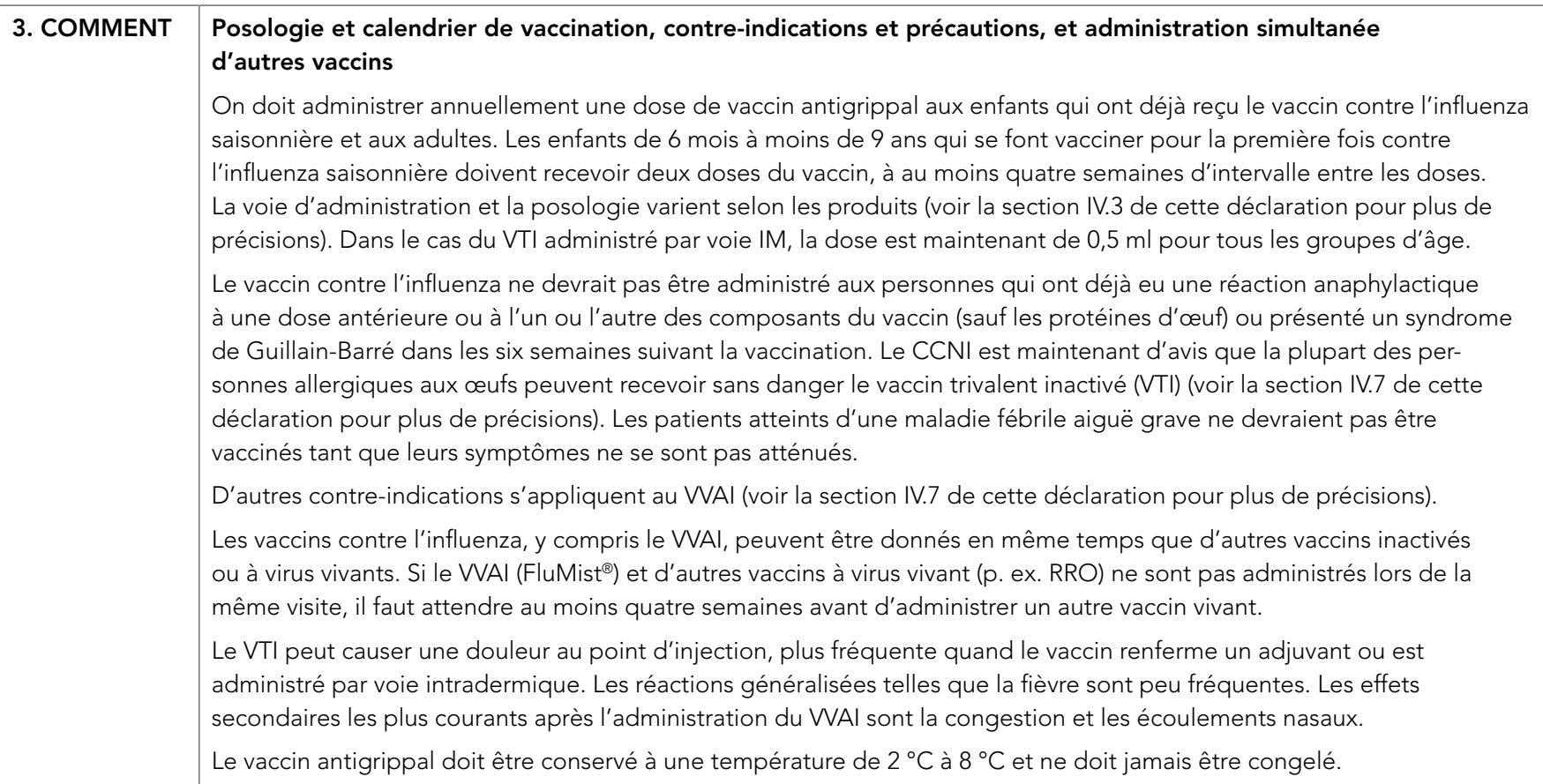

4. POURQUOI Points conseils que les vaccinateurs doivent souligner aux patients en expliquant les recommandations.

La vaccination est le moyen le plus efficace de prévenir la grippe.

Chaque année, on fabrique un nouveau vaccin antigrippal afin de protéger la population contre les souches virales qu'on s'attend à voir circuler durant la saison grippale suivante. Même si les souches incluses dans le vaccin restent les mêmes, la vaccination annuelle est nécessaire afin de maximiser la protection.

Le vaccin annuel contre l'influenza est recommandé pour l'ensemble de la population canadienne, mais plus particulièrement chez les personnes qui présentent un risque élevé de complications liées à l'influenza, chez les personnes qui pourraient leur transmettre la grippe et chez celles qui fournissent des services communautaires essentiels.

Le vaccin antigrippal est sûr et bien toléré. 


\section{Introduction}

\section{I.1 APERÇU ET RÉSUMÉ DES CHANGEMENTS}

La présente déclaration vise à exposer les recommandations du CCNI relativement à l'administration du vaccin contre l'influenza pour la saison 2012-2013.

Conformément aux recommandations de l'Organisation mondiale de la Santé pour l'hémisphère Nord, le vaccin trivalent pour la saison 2012-2013 contient les antigènes suivants :

- Virus analogue à $\mathrm{A} /$ California/7/2009 (H1N1)pdm09;

- Virus analogue à A/Victoria/361/2011 (H3N2);

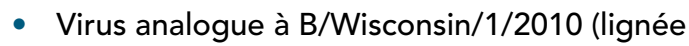
B Yamagata).

La déclaration de 2012-2013 met à jour l'information concernant la saison grippale 2011-2012 et les renseignements sur les huit vaccins antigrippaux homologués dont l'usage a été approuvé au Canada : Influvac ${ }^{\circledR}$, Fluviral $^{\circledR}$, Vaxigrip ${ }^{\circledR}$, Intanza ${ }^{\mathrm{MD}}$, FluMist ${ }^{\circledR}$, Agriflu $^{\circledR}$, Fluad $^{\circledR}$ et Fluzone ${ }^{\circledR}$ (voir le tableau 1 pour connaître les caractéristiques des produits).

Depuis la « Déclaration sur la vaccination antigrippale pour la saison 2011-2012 », deux changements ont été apportés à la liste des personnes pour lesquelles le vaccin antigrippal est recommandé. Le CCNI a maintenant inclus les enfants âgés de 24 à 59 mois parmi les personnes pour qui le vaccin saisonnier contre l'influenza est recommandé.

Autrement dit, TOUS les enfants de 6 à 59 mois, peu importe l'affection chronique dont ils sont atteints, font partie des groupes pour lesquels la vaccination antigrippale saisonnière est recommandée. Par conséquent, les personnes qui prennent habituellement soin d'enfants âgés de 6 à 59 mois, que ce soit à l'extérieur ou à domicile, devraient aussi recevoir le vaccin recommandé contre l'influenza saisonnière.

Les programmes d'immunisation devraient continuer de cibler les personnes qui présentent un risque élevé de complications grippales, celles qui pourraient leur transmettre la grippe et celles qui assurent des services communautaires essentiels (voir la section V.2 et le tableau 4 pour plus de détails). Le lecteur trouvera dans le reste de la déclaration de 2012-2013 des détails complets, y compris des recommandations destinées aux sujets immunodéprimés et atteints d'autres affections chroniques.
Dans la déclaration de la saison 2012-2013, le CCNI recommande d'éviter la revaccination chez les personnes qui ont présenté un syndrome de Guillain-Barré dans les six semaines suivant une vaccination précédente contre I'influenza. Ceci représente un changement des huit semaines mentionnées dans la Déclaration sur la vaccination antigrippale pour la saison 2011-2012.

La section «Stratégies visant à atténuer l'impact de I'influenza » a été retirée; on peut la retrouver dans la Déclaration sur la vaccination antigrippale pour la saison 2011-2012 au : http://www.phac-aspc.gc.ca/publicat/ ccdr-rmtc/11vol37/acs-dcc-5/index-fra.php.

\section{I.2 CONTEXTE}

Les virus de l'influenza de type A sont classés en sous-types en fonction de deux protéines de surface : I'hémagglutinine $(\mathrm{H})$ et la neuraminidase $(\mathrm{N})$. Trois sous-types d'hémagglutinine $(\mathrm{H} 1, \mathrm{H} 2$ et $\mathrm{H} 3)$ et deux sous-types de neuraminidase (N1 et N2) font partie des virus de l'influenza A qui ont causé des épidémies chez les humains. L'immunité contre les protéines $\mathrm{H}$ et $\mathrm{N}$ réduit la probabilité d'infection ainsi que la gravité de la maladie lorsque survient une infection.

Depuis le milieu des années 80 , les virus de l'influenza de type $B$ ont évolué en deux lignées antigéniquement distinctes, représentées par des virus analogues à $B /$ Yamagata/16/88 et B/Victoria/2/87. Les virus appartenant aux lignées $B /$ Yamagata comme B/Victoria contribuent de façon variable à l'épidémiologie de l'influenza chaque année.

Avec le temps, il se produit une variation antigénique (dérive antigénique) des souches à l'intérieur d'un sous-type de l'influenza A ou d'une lignée B. Comme une dérive antigénique peut toucher un ou plusieurs composants du vaccin antigrippal, il faut habituellement reformuler chaque année les vaccins antigrippaux saisonniers. Ces derniers contiennent des quantités standard de la protéine $\mathrm{H}$ de souches de semence, représentatives des deux sous-types humains du virus de l'influenza A (H3N2 et H1N1) et d'une des deux lignées du virus B (Yamagata ou Victoria). Les anticorps sériques anti-H produits contre un sous-type de virus $A$ ne devraient conférer qu'une protection légère voire aucune protection contre les souches appartenant à l'autre sous-type. II faut effectuer des études plus poussées pour déterminer si le vaccin peut induire une protection immunitaire contre I'ensemble des lignées B; cette protection peut aussi dépendre de l'âge du sujet ou de son exposition antérieure aux antigènes des deux lignées $B^{(1)-(5)}$. 


\section{Méthodes}

Les détails sur le processus d'élaboration des déclarations du CCNI fondé sur des données probantes figurent dans le document Recommandations pour l'immunisation fondées sur des données probantes - Méthodes du Comité consultatif national de l'immunisation (RMTC, janvier 2009), qui est affiché à l'adresse suivante : http://www.phac-aspc. gc.ca/publicat/ccdr-rmtc/09vol35/acs-1/index-fra.php.

Le Groupe de travail sur l'influenza (GTI) formule les recommandations sur la vaccination antigrippale annuelle et les soumet à l'attention du CCNI. II examine diverses questions, notamment : le fardeau de la maladie et les populations cibles; l'innocuité, l'immunogénicité, l'efficacité potentielle et réelle des vaccins contre I'influenza; les calendriers de vaccination et d'autres aspects de la vaccination antigrippale.

Pour élaborer la déclaration de 2012-2013, le GTI et le CCNI ont cerné les principales questions devant guider les recensions des écrits et les synthèses particulières,

\section{III. Épidémiologie}

\section{III.1 DESCRIPTION DE LA MALADIE}

On estime qu'entre 10 et $20 \%$ de la population contracte une infection grippale chaque année ${ }^{(6)}$, le taux général annuel d'attaque variant entre 5 et $10 \%$ chez les adultes et entre 20 et $30 \%$ chez les enfants ${ }^{(7)}$. Les taux d'infection grippale sont les plus élevés chez les enfants, mais les maladies graves et les décès sont les plus nombreux chez les personnes âgées (> 65 ans) et celles qui souffrent d'une affection sous-jacente ${ }^{(8)}$. L'infection grippale est le plus souvent associée à une infection fébrile des voies respiratoires supérieures et inférieures. Certaines complications comme la pneumonie bactérienne secondaire et l'aggravation d'une affection préexistante peuvent causer une maladie grave. Il est difficile d'évaluer le fardeau réel de l'influenza, notamment les taux d'incidence, de mortalité et d'hospitalisation, car on n'effectue pas régulièrement de tests de détection pour confirmation laboratoire du diagnostic ou ceux-ci sont réalisés trop tard. Le nombre d'hospitalisations liées à la grippe est toutefois estimé à plus de 20000 par année(9)(10); jusqu'à 4000 Canadiens, surtout des personnes âgées, peuvent mourir des suites d'une pneumonie liée à la grippe, et d'autres peuvent décéder suite à d'autres complications grippales graves ${ }^{(11)}$. notamment l'examen des données concernant les enfants âgés de 24 à 59 mois. Après une évaluation critique de chacune des études et l'élaboration de tableaux sommaires cotant la qualité des données, des recommandations relatives à l'utilisation du vaccin antigrippal ont été proposées. L'analyse épidémiologique de la saison 2011-2012 a été préparée par le Centre de l'immunisation et des maladies respiratoires infectieuses de l'Agence de la santé publique du Canada (ASPC).

Les données et les recommandations proposées ont été présentées au CCNI le $1^{\text {er }}$ mai 2012. Après un examen approfondi des données, le Comité a procédé à un vote sur des recommandations précises. On trouvera dans le texte une description des considérations pertinentes, des justifications des décisions et des lacunes dans les connaissances. L'ASPC tient à jour de la documentation sur ces processus tout au long de l'exercice de synthèse des connaissances et d'élaboration des recommandations.

\section{III.2 SURVEILLANCE NATIONALE DE L'INFLUENZA DURANT LA SAISON 2011-2012}

\section{III.2.1 Répartition de la maladie}

Le Centre de l'immunisation et des maladies respiratoires infectieuses (CIMRI) de I'ASPC coordonne la surveillance nationale de l'influenza. Le programme Surveillance de I'influenza recueille des données et des éléments d'information de sources différentes afin de brosser un tableau national de l'activité grippale. Des détails sur la méthodologie employée par Surveillance de l'influenza ont déjà été présentés ${ }^{(12)}$.

Les renseignements fournis pour la saison 2011-2012 dans la présente déclaration ont été établis à partir des données de surveillance recueillies entre le 28 août 2011 et le 28 avril 2012, sauf indication contraire. Ces données sont préliminaires et les nombres pourraient varier à cause des retards dans la déclaration de cas. Pour obtenir des données plus à jour, le lecteur est invité à consulter le rapport annuel de Surveillance de l'influenza à l'adresse : http://www.phac-aspc.gc.ca/fluwatch/aiisr-raisi-fra.php. 
L'activité grippale au Canada est demeurée faible entre septembre 2011 et le début de février 2012, seules quelques régions faisant état d'une activité grippale accrue (dans les provinces de l'Ouest et en Ontario et au Québec). L'activité grippale a continué à s'intensifier tout au long des mois de février et de mars dans la plupart des régions du Canada et on a connu des pics d'activité vers la mi-mars. À la fin mars 2012, l'activité grippale avait commencé à décliner en général mais est demeurée élevée dans certaines régions (en Ontario, au Québec, les Prairies, et dans la région de l'Atlantique) jusqu'à la fin d'avril 2012 Depuis le début de la saison, 459 éclosions d'influenza ou de syndrome grippal (SG) ont été signalées, la majorité d'entre elles dans des établissements de soins de longue durée (55\%).

Depuis le début de la saison jusqu'au commencement de mars 2012, ce sont les virus A qui ont surtout été détectés. Depuis mars 2012, cependant, les virus de l'influenza de type B prédominent. En date du 28 avril 2012, 47,8\% (5 153/10 773) des virus grippaux détectés appartenaient au type $A$ ( $40,6 \%$ étaient des virus $A(H 3), 19,0 \%$ des virus $A$ (H1N1)pdm09 et 40,4\% n'ont pas été sous-typés), et $52,2 \%$ appartenaient au type B.

Des renseignements détaillés sur l'âge et le sous-type de virus ont été communiqués pour 84 \% (9 047) des 10773 cas confirmés en laboratoire. Les cas se répartissaient par groupe d'âge de la façon suivante : $21,2 \%$ avaient moins de 5 ans; $17,9 \%$ étaient âgés entre 5 et 19 ans; $22,2 \%$ avaient entre 20 et 44 ans; $15,3 \%$ entre 45 et 64 ans; $23,1 \%$ avaient 65 ans et plus; et 0,2\% étaient d'âge inconnu. Les plus fortes proportions des 792 cas infectés par le virus A (H1N1)pdm09 étaient âgés entre 20 et 44 ans (34\%) ou avaient moins de 5 ans ( $26 \%$ ). Les plus fortes proportions des 2008 cas infectés par le virus A (H3N2) faisaient partie du groupe des 65 ans et plus (34\%) et des 20 à 44 ans (22\%). Pour ce qui est des 4430 cas attribuables au virus B, les plus fortes proportions ont été relevées chez les 5 à 19 ans (25\%), les personnes âgées de plus de 65 ans (22\%) et les moins de 5 ans (22\%).

Entre le 1er septembre 2011 et le 3 mai 2012, le Laboratoire national de microbiologie (LNM) a caractérisé antigéniquement 1010 virus de l'influenza (196 A (H3N2), $182 \mathrm{~A}$ (H1N1) et $632 \mathrm{~B})$. Sur les 196 virus $A$ (H3N2), 177 (90,3 \%) étaient apparentés sur le plan antigénique à la souche vaccinale H3N2 pour 2011-2012 A/Perth/16/2009 alors que pour 19 virus $(9,7 \%)$, on a obtenu un titre plus faible avec un antisérum dirigé contre la souche A/Perth/16/2009. Sur les 182 virus A (H1N1) testés, 177 (97,3\%) étaient apparentés sur le plan antigénique à la souche vaccinale H1N1 A/California/07/2009 de 2011-2012, tandis que le titre de 5 virus (2,7\%) était réduit avec I'antisérum dirigé contre la souche A/California/07/2009. Sur les 632 virus B caractérisés, 315 (49,8\%) étaient antigéniquement apparentés à la souche vaccinale B/Brisbane/60/2008 (lignée Victoria) de 2011-2012; dans le cas d'un des 315 virus $B$, on a obtenu un titre plus faible avec un antisérum dirigé contre la souche $\mathrm{B} /$ Brisbane/ 60/2008. Les 317 virus $B$ restants (50,2\%) étaient antigéniquement apparentés à la souche de référence analogue au virus B/Wisconsin/01/2010, qui appartient à la lignée Yamagata.

\section{III.2.2 Surveillance des maladies graves Hospitalisations et décès chez les enfants} Entre le 1er septembre 2011 et le 28 avril 2012, les données préliminaires montrent que 524 cas d'hospitalisation associée à l'influenza chez des enfants (16 ans et moins) ont été signalés par l'entremise du réseau du Programme canadien de surveillance active de l'immunisation (IMPACT). De ce nombre, 230 (44\%) étaient dus à l'influenza A et 294 (56 \%) à l'influenza de type B. Les cas étaient répartis comme suit selon le groupe d'âge : $15 \%$ chez les nourrissons de moins de 6 mois; $20 \%$ chez les enfants de 6 à 24 mois; $31 \%$ chez les 2 à 4 ans; $23 \%$ chez les 5 à 9 ans; $10 \%$ chez les 10 à 16 ans. Cinq décès attribuables à I'influenza chez des enfants ont été signalés par les hôpitaux du réseau IMPACT jusqu'à maintenant cette saison et tous étaient associés à une infection par le virus B.

Des données préliminaires supplémentaires étaient disponibles pour $58 \%$ (264/453) des cas pédiatriques hospitalisés identifiés entre le début de la saison 2011-2012 et le 7 avril 2012. Au cours de la saison 2010-2011, environ $46 \%(122 / 264)$ des enfants infectés souffraient d'une maladie sous-jacente. Les antécédents de vaccination de 208 des 264 cas (79\%) ont été obtenus; $12 \%$ de ces cas (25/208) avaient été vaccinés contre l'influenza durant la saison 2011-2012. Environ $9 \%$ (24/264) des enfants atteints ont dû recevoir des soins intensifs. Les manifestations cliniques les plus fréquentes signalées chez les 264 cas étaient la fièvre (94\%), la toux (87 \%), la rhinite (65\%), la léthargie (55\%) et la détresse respiratoire (41\%). 


\section{Hospitalisations et décès chez les adultes}

Les cas d'hospitalisation associés à l'influenza chez les adultes sont signalés à l'ASPC par la majorité des provinces et des territoires au Canada, sauf la

Colombie-Britannique, le Québec et le Nouveau-Brunswick; seules les hospitalisations qui nécessitent des soins médicaux intensifs sont signalées par la Saskatchewan. Entre le $1^{\text {er }}$ septembre 2011 et le 28 avril 2012, 858 adultes (âgés de 20 ans et plus) ont été hospitalisés pour une grippe. La proportion de cas déclarés par groupe d'âge est la suivante : $18 \%$ chez les 20 à 44 ans; $27 \%$ chez 45 à 64 ans et $55 \%$ chez les 65 ans et plus. En date du 28 avril 2012, 73 décès associés à l'influenza ont été recensés chez des adultes, 78 \% d'entre eux chez des personnes de 65 ans et plus.

D'après l'information fournie $(n=831)$ par le Programme canadien de surveillance des infections nosocomiales (PCSIN) durant la saison grippale 2010-2011, environ $87 \%$ des cas hospitalisés chez les adultes souffraient d'une affection sous-jacente. Des renseignements sur la vaccination ont été obtenus pour $38 \%$ des cas (317/831); $43 \%$ d'entre eux (137/317) avaient reçu le vaccin antigrippal de 2010-2011. Environ $14 \%$ des cas chez les adultes durant la saison 2010-2011 ont dû recevoir des soins intensifs. Parmi les 831 adultes atteints de la grippe, 41 sont décédés, la majorité (71\%) était âgée de 65 ans et plus.

\section{III.3 SURVEILLANCE INTERNATIONALE DE L'INFLUENZA}

Entre septembre 2011 et janvier 2012, une activité grippale a été signalée en Afrique, dans les Amériques, en Asie, en Europe et en Océanie. Les virus grippaux A (H3N2) ont prédominé en Europe, dans de nombreux pays des Amériques et de l'Afrique du Nord et dans certains pays d'Asie. Les virus grippaux A (H1N1)pdm09 étaient très peu actifs en général, sauf dans certains pays d'Asie et des Amériques (y compris le Mexique). Les virus B ont circulé dans de nombreuses régions du monde et étaient prédominants dans certains pays (dont la Chine) ${ }^{(13)}$.

Même si la plupart des virus caractérisés tôt dans la saison 2011-2012 étaient apparentés sur le plan antigénique aux souches virales contenues dans le vaccin trivalent pour 2011-2012, il y avait des signes de dérive antigénique et génétique croissante dans les virus $A(H 3 N 2)$ qui ont circulé plus récemment, et la proportion de virus $B$ appartenant à la lignée Yamagata était en hausse par rapport à ceux de la lignée Victoria. L'OMS a donc recommandé un changement dans la composition de la prochaine préparation vaccinale destinée à l'hémisphère Nord pour la saison grippale 2012-2013 afin d'inclure un virus apparenté à A/Victoria/361/2011 (H3N2) et un virus analogue à B/Wisconsin/1/2010 de la lignée Yamagata, tout en conservant le virus apparenté à A/California/7/2009 (H1N1)pdm09(13).

\section{III.3.1 Nouveaux virus de l'influenza chez les humains ( $d$ 'origine aviaire et porcine)}

\section{Virus H5N1 de I'influenza aviaire humaine}

Actuellement, le virus H5N1 de l'influenza aviaire continue de circuler chez les volailles dans certains pays, en particulier en Asie. Entre le 1er septembre 2011 et le 2 mai 2012, l'OMS a fait état de 38 cas d'infection humaine par le virus de l'influenza aviaire $\mathrm{A}(\mathrm{H} 5 \mathrm{~N} 1)$ dans six pays : Indonésie $(n=11)$, Égypte $(n=16)$, Cambodge $(n=2)$, Vietnam $(n=4)$, Chine $(n=2)$ et Bangladesh $(n=3)$. Sur les 38 cas, 23 (61\%) ont été recensés chez des adultes ( $\geq 18$ ans) et 15 (39\%) chez des enfants. Trente-deux (84\%) des 38 cas ont dû être hospitalisés; $63 \%$ sont décédés ( $n=24 ; 15$ décès chez les adultes et 9 chez les enfants). De ces 38 cas, 19 cas (50\%) ont été exposés à des oiseaux malades ou morts alors que 15 autres cas (39\%) ont été exposés à des oiseaux (exposés à des volailles de basse-cour; impliqués dans la vente ou l'abattage de volaille ou de gibier d'eau). Ce virus H5N1 de l'influenza aviaire continue de causer des infections sporadiques chez les humains, notamment quelques cas de transmission interhumaine limitée chez des contacts très étroits. On ne signale jusqu'à maintenant aucun cas de transmission interhumaine ou communautaire soutenue ${ }^{(14)}$.

\section{Virus de l'influenza d'origine porcine chez les humains}

Les virus de l'influenza porcine n'infectent habituellement pas les humains; il arrive cependant que des infections humaines sporadiques par des virus grippaux qui infectent normalement les porcs surviennent. Entre décembre 2005 et le 13 avril 2012 aux États-Unis, 36 cas (27 chez des enfants de 18 ans et moins et 9 chez des adultes) d'infection humaine par des variantes du virus d'origine porcine ont été enregistrés. Les 36 cas se sont tous rétablis. Une exposition directe ou indirecte à des porcs avant l'apparition de la maladie a été découverte dans la majorité des cas $(72 \%)^{(15)}$. 
Sur les 13 cas infectés par des variantes du virus $\mathrm{H} 3 \mathrm{~N} 2$ (H3N2v) contenant le gène $\mathrm{M}$ de l'influenza H1N1 de 2009 qui ont été signalés depuis juillet 2011, plus de la moitié avaient été exposés à des porcs. On soupçonne une transmission interhumaine limitée du H3N2v dans des cas survenus en lowa et en Virginie-Occidentale en novembre 2011 $1^{(16)}$.

\section{III.4 RÉSISTANCE AUX ANTIVIRAUX}

Les détails des profils de résistance aux antiviraux des souches de l'influenza en circulation établis dans le cadre du programme de surveillance régulière du LNM sont communiqués par le programme Surveillance de l'influenza. Du 1er septembre 2011 au 3 mai 2012, le LNM a testé 990 virus grippaux afin de détecter une résistance à l'oseltamivir (test phénotypique et/ou séquençage) et 989 virus grippaux pour déceler la résistance au zanamivir (test phénotypique); tous les virus testés étaient sensibles à l'oseltamivir et au zanamivir. Au total, 591 virus de I'influenza A (328 H3N2 et $263 \mathrm{H} 1 \mathrm{~N} 1)$ ont été soumis à une épreuve de sensibilité à l'amantadine; tous les virus testés étaient résistants sauf un virus $A$ (H3N2).

\section{Vaccin antigrippal saisonnier}

\section{IV.1 PRÉPARATIONS HOMOLOGUÉES AU CANADA}

\section{IV.1.1 Survol}

Huit vaccins trivalents contre l'influenza saisonnière sont actuellement homologués au Canada, soit sept vaccins inactivés et un vaccin à virus vivant atténué :

- Agriflu ${ }^{\circledast}$ (Novartis)

- Fluad $^{\circledR}$ (Novartis)

- FluMist ${ }^{\circledR}$ (AstraZeneca) vaccin vivant atténué

- Fluviral ${ }^{\circledR}$ (GlaxoSmithKline)

- Fluzone $^{\circledR}$ (Sanofi Pasteur)

- Influvac ${ }^{\circledast}$ (Abbot)

- IntanzaMD (Sanofi Pasteur) préparations de $9 \mu \mathrm{g}$ et de $15 \mu \mathrm{g}$

- Vaxigrip ${ }^{\circledast}$ (Sanofi Pasteur)

Dans la présente déclaration, nous décrirons l'emploi de chacun de ces huit vaccins. Le lecteur trouvera plus $d^{\prime}$ information sur les vaccins IntanzaMD, FluMist ${ }^{\circledR}$ et Fluad ${ }^{\circledR}$ dans les déclarations supplémentaires du CCNI portant sur chacun de ces produits ${ }^{(17)-(19)}$.

La sélection des souches incluses dans le vaccin annuel se fait à partir des caractéristiques antigéniques des souches de virus en circulation et émergentes. Tous les fabricants de vaccins antigrippaux au Canada ont confirmé à la Direction des produits biologiques et des thérapies génétiques de Santé Canada que les vaccins qui seront commercialisés au Canada pour la saison 2012-2013 contiennent les trois souches antigéniques recommandées par l'OMS pour l'hémisphère Nord. Les fabricants de vaccins peuvent utiliser des souches antigéniquement équivalentes à cause de leurs propriétés de croissance.
On trouvera plus de détails sur la composition de chaque vaccin et une brève description du processus de fabrication dans la monographie de produit. Nous avons cependant signalé ci-dessous et dans le tableau 2 certains détails pertinents clés et différences entre les produits.

Les produits sont tous fabriqués à l'aide d'une méthode de culture dans des œufs embryonnés de poule et peuvent ainsi contenir une infime quantité de résidus de protéines d'œuf. Tous les vaccins antigrippaux actuellement sur le marché au Canada sont jugés sûrs pour les personnes souffrant d'une allergie au latex.

La décision d'inclure certains vaccins antigrippaux dans les programmes provinciaux ou territoriaux publics dépend de multiples facteurs tels que l'évaluation des coûts-avantages et d'autres critères relatifs aux programmes et aux opérations, comme la durée de conservation et les stratégies de mise en œuvre. Les programmes publics offriront en 2012-2013, dans une plus ou moins grande mesure, six des huit vaccins homologués, notamment :

- Fluviral ${ }^{\circledR}$ (GlaxoSmithKline)

- Vaxigrip $^{\circledR}$ (Sanofi Pasteur)

- IntanzaMD (Sanofi Pasteur), formulation de $15 \mu \mathrm{g}$

- FluMist $^{\circledR}$ (AstraZeneca)

- Agriflu ${ }^{\circledast}$ (Novartis)

- Fluad $^{\circledR}($ Novartis).

Les produits ne seront pas tous offerts dans toutes les provinces et tous les territoires, et la disponibilité de certains produits peut être très limitée; il faut donc consulter les autorités de sa province ou de son territoire pour avoir plus de détails sur les produits accessibles. 


\section{IV.1.2 Vaccin trivalent inactivé (VTI) contre l'influenza}

Les sept VTI actuellement homologués au Canada comprennent à la fois des vaccins à virion fragmenté et des vaccins sous-unitaires, qui contiennent de façon standard les mêmes hémagglutinines $(H)$. La quantité de neuraminidase dans les vaccins n'est pas standardisée. Il existe actuellement six VTI homologués qui peuvent être injectés par voie IM, cinq sans adjuvant et un avec adjuvant. Un septième VTI est injectable uniquement par voie intradermique.

\section{VTI administré par voie intramusculaire sans adjuvant}

Les cinq vaccins antigrippaux inactivés pour injection IM sans adjuvant sont les suivants :

- Fluvira ${ }^{\circledR}$ (GlaxoSmithKline)

- Vaxigrip ${ }^{\circledR}$ (Sanofi Pasteur)

- Fluzone ${ }^{\circledR}$ (Sanofi Pasteur)

- Agriflu ${ }^{\circledR}($ Novartis $)$

- Influvac ${ }^{\circledast}$ (Abbott)

\section{VTI contenant l'adjuvant MF59 administré par voie intramusculaire}

Fluad $^{\circledR}$ (Novartis) renferme l'adjuvant MF59, une émulsion de type huile dans eau composée de squalène (phase huileuse), stabilisée par des agents de surface, le polysorbate 80 et le trioléate de sorbitan, dans un tampon de citrate.

\section{VTI administré par voie intradermique sans adjuvant}

IntanzaMD (Sanofi Pasteur) pour injection intradermique est présenté sous deux formulations :

- $9 \mu \mathrm{g}$ de $\mathrm{H}$ (pour chacune des trois souches) par 0,1 ml à l'intention des personnes de 18 à 59 ans et

- $15 \mu \mathrm{g}$ de $\mathrm{H}$ (pour chacune des trois souches) par 0,1 ml à l'intention des personnes de 60 ans et plus.

\section{IV.1.3 Vaccin à virus vivant atténué (VVAl) contre l'influenza}

FluMist $^{\circledR}$ est un vaccin à virus vivant atténué administré par vaporisation intranasale. Il est approuvé pour les personnes de 2 à 59 ans. Chaque dose de $0,2 \mathrm{ml}$ de FluMist $^{\circledR}(0,1 \mathrm{ml}$ dans chaque narine) contient $10^{6,5,7,5}$ unités de foyers fluorescents (UFF) de virus vivants atténués et réassortis de chacune des trois souches cultivées dans des œufs exempts de pathogènes. Les souches du virus de I'influenza contenues dans FluMist ${ }^{\circledR}$ sont adaptées au froid et thermosensibles, de sorte qu'elles se répliquent dans la muqueuse nasale plutôt que dans les voies respiratoires inférieures; comme elles sont atténuées, elles ne causent pas le syndrome grippal classique. 
TABLEAU 2 : Caractéristiques des vaccins antigrippaux homologués au Canada, 2012-2013

\begin{tabular}{|c|c|c|c|c|c|c|c|c|}
\hline $\begin{array}{l}\text { Fabricant } \\
\text { Nom du produit }\end{array}$ & $\begin{array}{l}\text { Abbott } \\
\text { Influvac }^{\circledR}\end{array}$ & $\begin{array}{l}\text { GSK } \\
\text { Fluviral }^{\circledR}\end{array}$ & $\begin{array}{l}\text { Novartis } \\
\text { Agriflu }^{\circledR}\end{array}$ & $\begin{array}{l}\text { Novartis } \\
\text { Fluad }^{\circledR}\end{array}$ & $\begin{array}{l}\text { Sanofi Pasteur } \\
\text { Vaxigrip }^{\circledR}\end{array}$ & $\begin{array}{l}\text { Sanofi Pasteur } \\
\text { FluZone }{ }^{\circledR}\end{array}$ & $\begin{array}{l}\text { Sanofi Pasteur } \\
\text { IntanzaMD }\end{array}$ & $\begin{array}{l}\text { AstraZeneca } \\
\text { FluMist }^{\circledR}\end{array}$ \\
\hline $\begin{array}{l}\text { Caractéristiques } \\
\text { du produit }\end{array}$ & VTI & $\mathrm{VTI}$ & VTI & VTI & VTI & VTI & VTI & WAI \\
\hline Type de vaccin & $\begin{array}{l}\text { Inactivé } \\
\text { - sous-unitaire }\end{array}$ & $\begin{array}{l}\text { Inactivé - } \\
\text { virion } \\
\text { fragmenté }\end{array}$ & $\begin{array}{l}\text { Inactivé - } \\
\text { sous-unitaire }\end{array}$ & $\begin{array}{l}\text { Inactivé - } \\
\text { sous-unitaire }\end{array}$ & $\begin{array}{l}\text { Inactivé - } \\
\text { virion } \\
\text { fragmenté }\end{array}$ & $\begin{array}{l}\text { Inactivé - } \\
\text { virion } \\
\text { fragmenté }\end{array}$ & $\begin{array}{l}\text { Inactivé - } \\
\text { virion } \\
\text { fragmenté }\end{array}$ & Vivant atténué \\
\hline $\begin{array}{l}\text { Voie } \\
\text { d'administration }\end{array}$ & $\mathrm{IM}$ & IM & $\mathrm{IM}$ & $\mathrm{IM}$ & $\mathrm{IM}$ & $\mathrm{IM}$ & $\begin{array}{l}\text { Intradermique } \\
\text { (ID) }\end{array}$ & $\begin{array}{l}\text { Vaporisation } \\
\text { intranasale }\end{array}$ \\
\hline $\begin{array}{l}\text { Groupe d'âge } \\
\text { pour lequel le } \\
\text { vaccin est } \\
\text { approuvé }\end{array}$ & $\geq 18$ ans & $\geq 6$ mois & $\geq 6$ mois & $\geq 65$ ans & $\geq 6$ mois & $\geq 6$ mois & $\geq 18$ ans & $2-59$ ans \\
\hline $\begin{array}{l}\text { Quantité } \\
\text { d'antigènes } \\
\text { (de chacune des } \\
\text { trois souches) }\end{array}$ & $\begin{array}{l}15 \mu \mathrm{g} \mathrm{H} \\
\text { /dose de } \\
0,5 \mathrm{ml}\end{array}$ & $\begin{array}{l}15 \mu \mathrm{g} \mathrm{H} \\
\text { /dose de } \\
0,5 \mathrm{ml}\end{array}$ & $\begin{array}{l}15 \mu \mathrm{g} \mathrm{H} \\
\text { /dose de } \\
0,5 \mathrm{ml}\end{array}$ & $\begin{array}{l}15 \mu \mathrm{g} \mathrm{H} \\
\text { /dose de } \\
0,5 \mathrm{ml}\end{array}$ & $\begin{array}{l}15 \mu \mathrm{g} \mathrm{H} \\
\text { /dose de } \\
0,5 \mathrm{ml}\end{array}$ & $\begin{array}{l}15 \mu \mathrm{g} \mathrm{H} \\
\text { /dose de } \\
0,5 \mathrm{ml}\end{array}$ & $\begin{array}{l}9 \mu \mathrm{g} \mathrm{H} / 0, \\
1 \mathrm{ml} \\
\text { (18-59 ans) } \\
15 \mu \mathrm{g} \mathrm{H} / 0,1 \mathrm{ml} \\
\text { (60 ans et plus) }\end{array}$ & $\begin{array}{l}10^{6,5-7,5} \mathrm{UFF} \\
\text { virus vivants } \\
\text { atténués et } \\
\text { réassortis/dose } \\
\text { de } 0,2 \mathrm{ml}\end{array}$ \\
\hline Adjuvant & Non & Non & Non & $\begin{array}{l}\text { MF59 (émulsion } \\
\text { huile dans eau) }\end{array}$ & Non & Non & Non & Non \\
\hline $\begin{array}{l}\text { Présentations } \\
\text { offertes }\end{array}$ & $\begin{array}{l}\text { Seringues } \\
\text { pré-remplies à } \\
\text { dose unique } \\
\text { avec ou sans } \\
\text { aiguille }\end{array}$ & $\begin{array}{l}\text { Fiole } \\
\text { multi-dose } \\
\text { de } 5 \mathrm{ml}\end{array}$ & $\begin{array}{l}\text { Seringues } \\
\text { pré-remplies à } \\
\text { dose unique } \\
\text { sans aiguille }\end{array}$ & $\begin{array}{l}\text { Seringues } \\
\text { pré-remplies à } \\
\text { dose unique } \\
\text { sans aiguille }\end{array}$ & $\begin{array}{l}\text { Fiole } \\
\text { multi-dose de } \\
5 \text { ml, ampoule } \\
\text { uni-dose, } \\
\text { seringues } \\
\text { pré-remplies } \\
\text { à dose unique } \\
\text { avec ou sans } \\
\text { aiguille }\end{array}$ & $\begin{array}{l}\text { Fiole } \\
\text { multi-dose de } \\
5 \mathrm{ml} \text {, ampoule } \\
\text { uni-dose, } \\
\text { seringues } \\
\text { pré-remplies à } \\
\text { dose unique } \\
\text { avec ou sans } \\
\text { aiguille }\end{array}$ & $\begin{array}{l}\text { Seringues } \\
\text { pré-remplies à } \\
\text { dose unique } \\
\text { avec système } \\
\text { de micro- } \\
\text { injection } \\
\text { Deux } \\
\text { formulations } \\
\text { (comme } \\
\text { ci-dessus) }\end{array}$ & $\begin{array}{l}\text { Vaporisateur } \\
\text { de verre } \\
\text { pré-rempli à } \\
\text { usage unique }\end{array}$ \\
\hline $\begin{array}{l}\text { Durée de } \\
\text { conservation } \\
\text { après la } \\
\text { perforation } \\
\text { des fioles } \\
\text { multi-doses }\end{array}$ & s.o. & 28 jours & s.o. & s.o. & 7 jours & Non indiquée & s.o. & s.o. \\
\hline Thimérosal & Non & Oui & Non & Non & $\begin{array}{l}\text { Oui - fioles } \\
\text { multi-doses } \\
\text { seulement }\end{array}$ & $\begin{array}{l}\text { Oui - fioles } \\
\text { multi-doses } \\
\text { seulement }\end{array}$ & Non & Non \\
\hline $\begin{array}{l}\text { Antibiotiques } \\
\text { (traces) }\end{array}$ & Gentamicine & Aucun & $\begin{array}{l}\text { Kanamycine } \\
\text { Néomycine }\end{array}$ & $\begin{array}{l}\text { Kanamycine } \\
\text { Néomycine }\end{array}$ & Néomycine & Néomycine & Néomycine & Gentamicine \\
\hline $\begin{array}{l}\text { Autres } \\
\text { ingrédients } \\
\text { non médicinaux } \\
\text { pertinents sur } \\
\text { le plan clinique* }\end{array}$ & $\begin{array}{l}\text { Protéines } \\
\text { d'œuf } \\
\text { Formaldéhyde } \\
\text { Bromure de } \\
\text { cétyltriméthyl- } \\
\text { ammonium } \\
\text { (CTAB) } \\
\text { Polysorbate } 80\end{array}$ & $\begin{array}{l}\text { Protéines } \\
\text { d'œuf } \\
\text { Formaldéhyde } \\
\text { Désoxycholate } \\
\text { de sodium } \\
\text { Saccarose }\end{array}$ & $\begin{array}{l}\text { Protéines } \\
\text { d'œuf } \\
\text { Formaldéhyde } \\
\text { Polysorbate } 80 \\
\text { CTAB }\end{array}$ & $\begin{array}{l}\text { Protéines } \\
\text { d'œuf } \\
\text { Formaldéhyde } \\
\text { Polysorbate 80, } \\
\text { CTAB }\end{array}$ & $\begin{array}{l}\text { Protéines } \\
\text { d'œuf } \\
\text { Formaldéhyde } \\
\text { Triton X-100 }\end{array}$ & $\begin{array}{l}\text { Protéines } \\
\text { d'œuf } \\
\text { Formaldéhyde } \\
\text { Triton X-100 } \\
\text { Gélatine } \\
\text { Saccarose }\end{array}$ & $\begin{array}{l}\text { Protéines } \\
\text { d'œuf } \\
\text { Formaldéhyde } \\
\text { Triton X-100 }\end{array}$ & $\begin{array}{l}\text { Protéines } \\
\text { d'œuf } \\
\text { Hydrolysat } \\
\text { de gélatine } \\
\text { Saccharose } \\
\text { Arginine } \\
\text { Glutamate } \\
\text { monosodique }\end{array}$ \\
\hline
\end{tabular}

* Prière de consulter la monographie de produit pour obtenir la liste complète des ingrédients non médicinaux et des excipients. ABRÉVIATIONS : CTAB (bromure de cétriminium), UFF (unités de foyers fluorescents), GSK (GlaxoSmithKline), H (hémagglutinine), ID (intradermique), IM (intramusculaire), WAI (vaccin à virus vivant atténué), VTI (vaccin trivalent inactivé) 


\section{IV.2 EFFICACITÉ POTENTIELLE ET RÉELLE ET IMMUNOGÉNICITÉ}

\section{IV.2.1 Efficacité potentielle et réelle}

De nombreuses études montrent que le vaccin contre I'influenza est efficace et prévient plus efficacement I'influenza confirmée en laboratoire que les affections répondant à la définition clinique de la maladie ${ }^{(20)}$. Chez les enfants en santé (âgés de 18 ou de 16 ans ou moins), une recension systématique et des méta-analyses ont montré que l'efficacité potentielle du vaccin variait entre 59 et $82 \%$ contre l'influenza confirmée en laboratoire, entre 54 et $63 \%$ contre l'influenza sérologiquement confirmée et entre 33 et $36 \%$ contre la maladie clinique ${ }^{(21)-(23)}$. Chez les enfants, le WAI est potentiellement plus efficace que le VTI. On trouvera d'autres détails dans la déclaration sur Flumist ${ }^{\circledR}$ au : http://www.phac-aspc.gc.ca/publicat/ccdr-rmtc/11vol37/ acs-dcc-7/index-fra.php et dans l'Annexe 1 de la Déclaration de 2012-2013.

Dans une recension systématique portant sur des adultes en santé, l'efficacité réelle du vaccin inactivé contre le syndrome grippal s'élevait à $30 \%$ (IC à $95 \%$ : 17-41\%) et l'efficacité potentielle contre l'influenza confirmée en laboratoire atteignait 80 \% (IC à 95 \% : 56-91\%) lorsque la souche vaccinale était appariée aux souches en circulation et que l'activité grippale était importante ${ }^{(24)}$. Une méta-analyse récente a établi à $50 \%$ l'efficacité potentielle du vaccin chez les adultes en santé (IC à $95 \%$ : 27-65\%) durant certaines saisons au cours desquelles le vaccin ne concordait pas avec les virus en circulation; cette discordance est cependant relative et le degré de protection croisée devrait varier ${ }^{(25)-(27)}$.

Chez les personnes âgées, l'efficacité réelle du vaccin se situe à la moitié de celle chez les adultes en santé et varie selon le résultat clinique et la population étudiée ${ }^{(28)(29)}$. Des recensions systématiques ont également révélé que le vaccin antigrippal contribue à faire baisser l'incidence de la pneumonie, des hospitalisations et des décès chez les personnes âgées ${ }^{(29)}$ et réduit les exacerbations chez les personnes souffrant d'une maladie pulmonaire obstructive chronique ${ }^{(30)}$. Dans des études d'observation, on a constaté que la vaccination abaissait le nombre de consultations médicales, d'hospitalisations et de décès chez les personnes à risque élevé de 18 à 64 ans $^{(31)}$, le nombre d'hospitalisations pour une maladie cardiaque et un AVC chez les personnes âgées ${ }^{(32)}$ et le nombre d'hospitalisations et de décès chez les personnes diabétiques de 18 ans et plus $^{(33)}$. De plus en plus, on fait appel à la prudence dans l'interprétation des études d'observation qui utilisent des résultats cliniques non spécifiques et ne tiennent pas compte des différences dans l'état fonctionnel ou dans les comportements en matière de santé(34)-(39).

L'efficacité potentielle du vaccin peut être plus faible dans certaines populations (p. ex. personnes immunodéprimées, âgées) que chez les adultes en santé. Cette plus faible efficacité potentielle ne devrait pas cependant empêcher de vacciner les personnes qui courent un risque élevé de maladies associées à l'influenza, car il est possible que le vaccin offre toujours une protection.

Sauf pour le WVAl, on dispose de données limitées sur l'efficacité potentielle des produits plus récents. Nous présentons de brefs résumés ci-dessous, mais pour plus de détails, il serait bon de consulter chacune des déclarations supplémentaires du CCNI pour IntanzaMD(17), FluMist $^{\circledR(18)}$ et Fluad ${ }^{\circledR(19)}$.

\section{VTI contenant l'adjuvant MF59}

$L^{\prime}$ efficacité potentielle de Fluad $^{\circledR}$ n'a pas été étudiée directement mais, selon les quelques études d'observation qui ont été effectuées, il semble que le risque d'hospitalisation pour la grippe et ses complications est moindre chez les personnes âgées que chez les sujets qui n'ont pas été vaccinés ou qui ont reçu un vaccin sous-unitaire sans adjuvant. Ces études comportent toutefois des limites méthodologiques importantes, qui compliquent leur interprétation(19).

\section{VTI sans adjuvant administré par voie intradermique}

L'efficacité potentielle d'IntanzaMD contre l'influenza confirmée en laboratoire et contre les complications grippales graves n'a pas été directement étudiée ${ }^{(17)}$.

\section{VAI}

Pour ce qui est de FluMist ${ }^{\circledR}$, un certain nombre d'études (WAI contre placebo et WAI contre VTI) portant sur des enfants et des adultes ont été réalisées ${ }^{(18)}$. Le WAI s'est révélé plus efficace chez les enfants de tous les groupes d'âge que le placebo, indépendamment des souches de virus en circulation et de leur concordance avec celles du vaccin. En outre, trois vastes études auxquelles ont participé des enfants de 6 mois à 18 ans ont montré que l'efficacité du WAI était supérieure à celle du VTI. La plupart des études comparatives chez des personnes de 18 à 59 ans ont par contre révélé que le WAl et le VTI avaient une efficacité potentielle similaire ou que le VTI était plus efficace ${ }^{(18)}$. 


\section{IV.2.2 Immunogénicité}

L'administration intramusculaire du VTI entraîne la production d'anticorps circulants de classe lgG dirigés contre les protéines virales hémagglutinine et neuraminidase ainsi qu'une réponse plus limitée des lymphocytes $T$ cytotoxiques. On croit que les réponses à médiation tant humorale que cellulaire jouent un rôle dans l'immunité contre l'influenza.

La production d'anticorps après la vaccination dépend de plusieurs facteurs, notamment l'âge du sujet vacciné, son exposition antérieure et subséquente aux antigènes et la présence d'un déficit immunitaire. Les titres d'anticorps humoraux, qui sont corrélés avec la protection vaccinale, sont généralement atteints deux semaines après la vaccination, mais une certaine protection peut être acquise plus tôt.

Bien qu'on pense que l'immunité humorale joue un rôle déterminant dans la protection contre les infections, on reconnaît de plus en plus l'importance de l'immunité à médiation cellulaire, en particulier la réponse des lymphocytes $T$ cytotoxiques aux composants viraux internes, dans la protection contre les complications graves de la grippe, en particulier celles associées aux variations dans les sous-types $\mathrm{H}$ (cassure et dérive) ${ }^{(40)}$.

Vu que les virus de l'influenza évoluent au fil des ans, l'immunité conférée durant une saison ne permettra pas de prévenir à coup sûr une infection causée par une souche ayant subi une dérive antigénique. C'est la raison pour laquelle on modifie habituellement chaque année les composants antigéniques du vaccin et qu'on recommande une vaccination annuelle. Même si les souches vaccinales n'ont pas changé, l'immunité diminue en général dans I'année qui suit la vaccination, et la revaccination confère une protection optimale pour la saison grippale à venir.

II n'a pas été démontré que l'administration annuelle répétée du vaccin antigrippal nuit à la réponse immunitaire chez le sujet vacciné.

S'il est vrai que la réponse immunitaire initiale des personnes âgées peut être plus faible contre certains composants du vaccin antigrippal, une recension des écrits n'a pas mis en évidence de baisse subséquente des anticorps qui serait plus rapide chez les personnes âgées que dans les groupes plus jeunes ${ }^{(41)}$.

La vaccination antigrippale peut entraîner la production de titres d'anticorps protecteurs chez un pourcentage important d'adultes et d'enfants présentant un déficit immunitaire, notamment les greffés, les sujets atteints d'une maladie proliférative du système hématopoiétique ou lymphatique et les patients infectés par le $\mathrm{VIH}^{(42)-(46)}$. Selon la plupart des études, l'administration d'une deuxième dose de vaccin chez les personnes âgées et les autres sujets dont la réponse immunitaire pourrait être compromise ne stimule pas l'immunité de façon cliniquement significative(45)(47)-(50).

\section{VTI contenant l'adjuvant MF59 ${ }^{\circledR}$}

Le mécanisme $d^{\prime}$ action de MF59 ${ }^{\circledR}$ n'est pas bien établi et il a surtout été étudié dans des modèles in vitro et murins. II ressort de ces études que MF59 ${ }^{\circledR}$ peut agir différemment par rapport aux adjuvants à base d'aluminium.

Ces études montrent que MF59 ${ }^{\circledR}$ agit localement au niveau des fibres musculaires pour créer un environnement immuno-stimulateur au point d'injection ${ }^{(51)}$. MF59 ${ }^{\circledR}$ accroît I'influx de phagocytes (p. ex. macrophages et monocytes) au point d'injection. Les phagocytes recrutés sont encore stimulés par $M F 59^{\circledR}$, ce qui accroît la production de chimiokines en vue d'attirer un plus grand nombre de cellules immunitaires innées et favorise la différenciation des monocytes en cellules dendritiques ${ }^{(52)(53)}$. MF59 ${ }^{\circledR}$ facilite par la suite l'internalisation de l'antigène par ces cellules dendritiques ${ }^{(53)(54)}$. Le nombre généralement plus élevé de cellules disponibles localement augmente la probabilité d'interaction entre une cellule présentant l'antigène et l'antigène, accroissant l'efficience du transport de I'antigène aux ganglions lymphatiques, ce qui résulte en une meilleure stimulation des lymphocytes $T^{(53)}$.

\section{VTI sans adjuvant administré par voie intradermique}

La peau constitue une puissante barrière immunitaire et contient un plus grand nombre de cellules dendritiques présentant l'antigène que les muscles. L'antigène grippal administré par voie intradermique a de grandes chances d'être en contact avec les cellules dendritiques locales. On pense aussi que le vaccin stimule l'immunité à médiation cellulaire ainsi que la production d'anticorps.

Le vaccin intradermique IntanzaMD entraîne une réponse immunitaire qui est comparable à celle produite par le VTI, avec ou sans adjuvant, administré par voie intramusculaire, les résultats variant selon la méthode sérologique utilisée ${ }^{(17)}$. Pour plus de détails, prière de consulter l'«Addendum à la déclaration sur le vaccin inactivé trivalent contre l'influenza saisonnière. Recommandations concernant l'utilisation du vaccin antigrippal trivalent inactivé intradermique (VTI-ID) » au : http://www.phac-aspc.gc.ca/publicat/ccdr-rmtc/ 11 vol37/acs-dcc-4/index-fra.php ${ }^{(17)}$. 


\section{VVAI}

Le WVI (FluMist $\left.{ }^{\circledR}\right)$, qui est administré par voie intranasale, produirait une réponse immunitaire qui imite celle associée à l'infection naturelle par des virus de type sauvage, produisant une immunité muqueuse et systémique. Les anticorps muqueux locaux protègent les voies respiratoires supérieures et peuvent jouer un rôle plus important dans la protection que les anticorps sériques.

Des études ont montré que la production d'anticorps H1 après l'administration du WVAl est prédicteur d'une protection. D'autres études sur l'efficacité potentielle ont cependant mis en évidence une protection malgré l'absence d'une réponse immunitaire importante ${ }^{(18)}$. Chez les enfants et les adolescents de 2 à 17 ans, l'immunogénicité du WAI s'est révélée égale ou supérieure à celle du VTI pour les trois souches du virus tandis que chez les adultes, le VTI conférait habituellement une protection plus grande que le WAI. On a observé des taux de séroconversion plus élevés chez les sujets séronégatifs au départ que chez les sujets initialement séropositifs, tant chez les enfants que chez les adultes ayant reçu le WAl, car l'immunité préexistante peut nuire à la réponse du sujet à un vaccin à virus vivant ${ }^{(18)}$. Pour plus de détails, prière de consulter la déclaration supplémentaire du CCNI relativement à FluMist ${ }^{\circledR}$ au : http://www.phac-aspc.gc.ca/ publicat/ccdr-rmtc/11vol37/acs-dcc-7/index-fra.php.

\section{Considérations relatives aux enfants}

Il est recommandé d'administrer deux doses aux enfants de moins de 9 ans qui reçoivent le vaccin contre l'influenza saisonnière pour la première fois afin d'assurer leur protection ${ }^{(55)(57)}$. Plusieurs chercheurs ont examiné la question pour savoir s'il faut administrer ces deux doses initiales au cours de la même saison ${ }^{(3)(58)(59)}$. Englund et coll. (3)(59) ont fait état de taux d'immunogénicité similaires chez les enfants de 6 à 23 mois, qu'ils aient reçu les deux doses au cours de la même saison ou au cours de deux saisons consécutives, lorsque les souches incluses dans le vaccin étaient les mêmes, ou pratiquement les mêmes, d'une année à l'autre. Les taux de séroprotection contre le composant $B$ étaient toutefois considérablement moins élevés lorsqu'un changement important dans la lignée $B$ était produit malgré la primovaccination au cours de la saison précédente ${ }^{(2)(3)}$. Il faudra étudier plus à fond la question de l'efficacité de la primovaccination-rappel lorsque la lignée du virus $B$ a subi une modification majeure d'une saison à l'autre(60).
Un essai comparatif randomisé (ECR) récent a été mené durant la saison grippale 2008-2009 auprès d'enfants de 6 à 23 mois ayant reçu le VTI. Lors du recrutement, les participants n'avaient jamais reçu de vaccin antigrippal ni souffert d'une grippe confirmée en laboratoire. Les résultats de l'étude semblent indiquer une amélioration modérée de la réponse immunitaire sans augmentation de la réactogénicité lorsque deux doses complètes $(0,5 \mathrm{ml})$ plutôt que deux demi-doses $(0,25 \mathrm{ml})$ de VTI étaient administrées à des nourrissons de 6 à 11 mois ${ }^{(61)}$.

\section{Il n'est pas recommandé d'administrer les vaccins antigrippaux actuellement disponibles aux nourrissons de moins de 6 mois.}

\section{IV.3 ADMINISTRATION DU VACCIN ANTIGRIPPAL : POSOLOGIE ET CALENDRIER}

Étant donné la variété de vaccins antigrippaux actuellement sur le marché, il importe que les praticiens connaissent les caractéristiques propres aux produits dont ils feront usage, notamment les indications relatives à l'âge, la voie d'administration, la posologie et le calendrier d'administration. La posologie recommandée pour chacun des produits homologués est présentée au tableau 3.

Les enfants de 6 mois à moins de 9 ans qui se font vacciner pour la première fois contre la grippe saisonnière doivent recevoir deux doses du vaccin, qu'il s'agisse du VTI ou du WAl, à au moins quatre semaines d'intervalle. Selon les données actuelles, les enfants admissibles de moins de 9 ans qui ont déjà reçu une dose ou plus du vaccin antigrippal saisonnier devraient recevoir une dose par saison grippale les années suivantes. Comme il est moins probable que les enfants de 6 à 23 mois aient déjà été sensibilisés au virus de l'influenza, il est bon de s'assurer que les deux doses du vaccin ont été effectivement administrées aux enfants de ce groupe d'âge qui n'ont jamais été vaccinés.

Les nourrissons et les tout-petits sont particulièrement touchés par la maladie, et leur réponse au VTI n'est pas aussi robuste que celle des enfants plus âgés. Des données publiées et inédites évoquent une amélioration modérée de la réponse immunitaire chez les nourrissons, sans augmentation de la réactogénicité, après I'administration de doses complètes du vaccin ${ }^{(62)}$. En conséquence, le CCNI recommande que les enfants de 6 à 35 mois reçoivent la dose complète $(0,5 \mathrm{ml})$ du VTI 


\section{au lieu de la demi-dose $(0,25 \mathrm{ml})$ recommandée} auparavant. Cette recommandation s'applique qu'on administre à l'enfant une dose ou deux doses de VTI'1.

Dans le cas des vaccins administrés par voie intramusculaire, on recommande de pratiquer l'injection dans le deltoïde chez les adultes et les enfants de 12 mois ou plus, et dans la région antérolatérale de la cuisse chez les nourrissons de 6 à 12 mois. Le point d'injection recommandé pour IntanzaMD qui est administré par voie intradermique à l'aide du système de micro-injection fourni avec le vaccin, est la région du deltoïde.

Le WAI (FluMist $\left.{ }^{\circledR}\right)$ ne doit être administré que par voie intranasale; il ne faut donc pas l'injecter par voie intramusculaire ou intradermique. Il est offert en vaporisateur pré rempli à usage unique contenant $0,2 \mathrm{ml}$ de vaccin. En tenant le dispositif à la verticale, on vaporise environ la moitié $(0,1 \mathrm{ml})$ du vaccin dans une narine, puis on retire le séparateur de dose pour vaporiser le reste du vaccin $(0,1 \mathrm{ml})$ dans l'autre narine.

TABLEAU 3 : Vaccins antigrippaux : posologie et voie d'administration recommandées, selon l'âge, pour la saison 2012-2013

\begin{tabular}{|c|c|c|c|c|c|}
\hline \multirow[t]{2}{*}{ Groupe d'âge } & VTI sans adjuvant $^{\dagger}$ & $\begin{array}{l}\text { VTI contenant } \\
\text { l'adjuvant MF59 } \\
\text { (Fluad }^{\circledR} \text { ) }\end{array}$ & $\begin{array}{l}\text { VTI pour } \\
\text { administration } \\
\text { intradermique } \\
\text { (Intanza }{ }^{\text {MD }} \text { ) }\end{array}$ & $\begin{array}{l}\text { VVAl } \\
\text { (FluMist }^{\circledR} \text { ) }\end{array}$ & \multirow[t]{2}{*}{$\begin{array}{l}\text { Nombre de } \\
\text { doses requises }\end{array}$} \\
\hline & IM & IM & ID & Intranasale & \\
\hline 6-23 mois & $0,5 \mathrm{ml}^{2}$ & - & - & - & 1 ou $2^{\star}$ \\
\hline $2-8$ ans & $0,5 \mathrm{ml}$ & - & - & $\begin{array}{l}0,2 \mathrm{ml} \\
(0,1 \mathrm{ml} \text { par narine })\end{array}$ & 1 ou $2^{\star}$ \\
\hline $9-17$ ans & $0,5 \mathrm{ml}$ & - & - & $\begin{array}{l}0,2 \mathrm{ml} \\
(0,1 \mathrm{ml} \text { par narine })\end{array}$ & 1 \\
\hline $18-59$ ans & $0,5 \mathrm{ml}$ & - & $0,1 \mathrm{ml}(9 \mu \mathrm{g} / \text { souche })^{\ddagger}$ & $\begin{array}{l}0,2 \mathrm{ml} \\
(0,1 \mathrm{ml} \text { par narine })\end{array}$ & 1 \\
\hline $60-64$ ans & $0,5 \mathrm{ml}$ & - & $0,1 \mathrm{ml}(15 \mu \mathrm{g} /$ souche $)$ & - & 1 \\
\hline$\geq 65$ ans & $0,5 \mathrm{ml}$ & $0,5 \mathrm{ml}$ & 0,1 ml (15 $\mu \mathrm{g} /$ souche) & - & 1 \\
\hline
\end{tabular}

$\mathrm{IM}=$ Intramusculaire $\quad \mathrm{ID}=$ Intradermique

* On doit administrer deux doses du vaccin aux enfants âgés de 6 mois à moins de 9 ans qui n'ont jamais reçu le vaccin antigrippal saisonnier, en respectant un intervalle d'au moins quatre semaines entre les doses. Les enfants admissibles de moins de 9 ans qui ont déjà reçu une dose ou plus du vaccin antigrippal saisonnier dans le passé devraient recevoir une dose par saison, au cours des années suivantes.

${ }^{\dagger}$ Influvac ${ }^{\circledR} \geq 18$ ans, Fluviral ${ }^{\circledR} \geq 6$ mois, Agriflu ${ }^{\circledR} \geq 6$ mois, Vaxigrip ${ }^{\circledR} \geq 6$ mois et FluZone ${ }^{\circledR} \geq 6$ mois.

₹ Dans le cas des adultes immunodéprimés, on devrait envisager d'administrer une préparation de 15 g pour améliorer la réponse immunitaire.

\section{IV.3.3 Administration du vaccin antigrippal à des personnes allergiques aux œufs}

Depuis la saison grippale 2011-2012, le CCNI a indiqué que les personnes allergiques aux œufs pouvaient se faire vacciner contre la grippe au moyen du VTI, sans avoir à subir au préalable de test cutané, une évaluation du risque de réaction allergique grave étant effectuée pour orienter le choix de la méthode de vaccination (recommandation du $\mathrm{CCNI}$ de catégorie $\mathrm{A})^{2}$. On trouvera ci-dessous des détails concernant les protocoles d'administration des vaccins.
À cause du manque de données, l'administration de FluMist $^{\circledR}$ à des personnes allergiques aux œufs n'est pas recommandée pour le moment. Les concentrations d'ovalbumine dans FluMist ${ }^{\circledR}$ sont cependant très faibles et une étude est en cours pour évaluer l'utilisation de FluMist ${ }^{\circledR}$ chez les personnes allergiques aux œufs. L'usage de ce vaccin sera réévalué dès qu'on aura accès à d'autres données.

\footnotetext{
${ }^{1,2}$ Ces renseignements diffèrent de ceux contenus dans la monographie de produit. Comme nous l'avons indiqué dans le préambule de la présente déclaration, les indications et les autres renseignements figurant dans la présente déclaration peuvent différer de l'information fournie dans les monographies de produit/ notices des fabricants canadiens.
} 
Bien que la teneur en ovalbumine du vaccin antigrippal fabriqué dans des œufs puisse varier d'une année à l'autre, d'un vaccin à l'autre et même d'un lot à l'autre du même vaccin ${ }^{(63)}(-65)$, les vaccins commercialisés au Canada sont approuvés selon la spécification européenne pour la teneur en ovalbumine, qui est actuellement de moins de $1,2 \mu \mathrm{g} / \mathrm{ml}$, la concentration associée à de faibles risques $d^{\prime}$ effets secondaires ${ }^{(66)}$.

Pour plus de détails sur les données et les lignes directrices sur lesquelles le CCNI s'est basé pour formuler cette recommandation, prière de consulter la «Déclaration sur la vaccination antigrippale pour la saisons 2011-2012 » à l'adresse suivante: http://www.phac-aspc.gc.ca/publicat/ ccdr-rmtc/11vol37/acs-dcc-5/index-fra.php.

\section{IV.3.3.1 Protocoles d'administration des vaccins aux personnes allergiques aux œufs}

La Société canadienne d'allergie et d'immunologie clinique (SCAIC) définit la gravité des allergies et établit des protocoles d'immunisation pour les personnes allergiques. Les vaccinateurs qui administrent les vaccins antigrippaux à des sujets allergiques aux œufs peuvent obtenir des détails sur le site Web de la SCAIC. Selon la SCAIC, I'allergie aux œufs se caractérise par des symptômes immédiats, 1 à 2 heures après l'exposition, tels que l'urticaire et l'œdème de Quincke, des symptômes respiratoires, gastro-intestinaux ou cardio-vasculaires, en plus des résultats de tests allergologues de confirmation (test cutané ou dosage des IgE spécifiques de l'œuf)(67). Le risque de réaction allergique grave ou d'anaphylaxie chez les personnes allergiques aux œufs peut être déterminé par l'évaluation des antécédents de réaction aux œufs. La SCAIC divise les patients allergiques aux œufs en deux catégories : ceux qui sont à faible risque de réaction allergique grave (réaction gastro-intestinale ou cutanée légère, ingestion de petites quantités d'œufs tolérée ou résultat positif au test cutané ou au dosage des IgE spécifiques de l'œuf lorsque l'exposition aux œufs n'est pas connue). Il y a également ceux qui sont à risque accru de réaction allergique grave (réaction respiratoire ou cardio-vasculaire antérieure, urticaire généralisée après une exposition à des œufs ou asthme mal maîtrisé).

Deux protocoles sont possibles pour l'administration du vaccin antigrippal aux personnes allergiques aux œufs, selon leur degré de risque de réaction allergique ${ }^{(67)}$. Les personnes à faible risque de réaction grave peuvent être vaccinées contre l'influenza à l'aide d'une seule dose.
L'approche graduelle en deux étapes est préconisée pour les personnes à risque accru de réaction allergique grave. Ces deux protocoles sont décrits comme suit:

1. Dose complète - La dose complète de vaccin est administrée en une seule injection, sans provocation à dose progressive. Il faut garder le patient en observation pendant 30 minutes après l'administration pour détecter d'éventuels symptômes.

2. Dose progressive en deux étapes - La dose est administrée progressivement en deux étapes. On commence par injecter $10 \%$ de la dose puis on observe le sujet pendant 30 minutes. En l'absence de symptômes, ou en présence de symptômes qui disparaissent spontanément, on administre le reste du vaccin, soit $90 \%$ de la dose, et on surveille le sujet pendant encore 30 minutes. S'il y a une réaction grave ou prolongée après l'administration de la dose initiale, il faut interrompre la vaccination et réévaluer la nécessité de vacciner le sujet contre l'influenza.

Dans les cas où l'on hésite fortement à suivre les recommandations ci-dessus chez un patient qui, par ailleurs, présente un risque de complications liées à l'influenza, il peut s'avérer nécessaire d'adresser le sujet à un allergologue. Si le sujet n'appartient pas à un groupe à risque élevé, on pourra réévaluer la nécessité de la vaccination.

Les enfants allergiques aux œufs qui tolèrent bien la dose initiale et qui ont besoin d'une deuxième dose du vaccin antigrippal au cours de la même saison peuvent recevoir la dose suivante, sans avoir à subir une provocation à dose progressive. Il doit s'agir du même produit, mais pas nécessairement du même lot.

La personne qui administre le vaccin doit discuter des risques d'éventuelles réactions, y compris une réaction anaphylactique après la période d'observation. Les personnes allergiques aux œufs qui reçoivent le vaccin antigrippal doivent toutes être surveillées durant la période recommandée de 30 minutes, qui pourra être prolongée (jusqu'à 60 minutes) comme mesure de précaution dans le cas des sujets à risque accru. Il faut avoir accès sans délai au traitement d'urgence et au matériel de réanimation requis pour faire face à une réaction anaphylactique grave.

Chaque année, il faut réévaluer en fonction de leur risque de réaction grave les personnes allergiques aux œufs avant de leur administrer le vaccin antigrippal sous forme de dose complète ou de dose progressive en deux étapes. 


\section{IV.4 CONDITIONS D'ENTREPOSAGE}

Le vaccin contre l'influenza doit être conservé à une température de $+2{ }^{\circ} \mathrm{C}$ à $+8{ }^{\circ} \mathrm{C}$ et ne doit pas être congelé. Prière de se reporter à chacune des monographies de produit pour obtenir plus de détails.

\section{IV.5 ADMINISTRATION SIMULTANÉE D'AUTRES VACCINS}

Le vaccin contre l'influenza, y compris le WAI, peut être donné en même temps que d'autres vaccins inactivés ou à virus vivant. Trois études ont évalué la réponse immunitaire et l'innocuité après l'administration concomitante du WAI avec le vaccin contre la rougeole, la rubéole et les oreillons $(\mathrm{RRO})^{(68)(69))}$, le vaccin contre la varicelle(69) et le vaccin antipoliomyélitique oral ${ }^{(70)}$. Les taux de séroréaction et les MGT pour le vaccin RRO ( $\geq 96 \%$ ) et le vaccin contre la varicelle ( $\geq 82 \%$ ) étaient similaires à ceux de l'administration concomitante de WAI ou de placebo. Les résultats de ces études montrent que le WAI peut être administré en toute sécurité en même temps que le vaccin $R R O$ et le vaccin contre la varicelle à de jeunes enfants dans la pratique clinique courante sans réduire l'immunogénicité ou l'innocuité d'aucun des vaccins. S'ils ne sont pas administrés au cours de la même consultation comme les autres vaccins à virus vivant (p. ex. RRO ou varicelle), les deux vaccins vivants devraient être administrés après un intervalle d'au moins quatre semaines.

Lorsqu'il faut faire plusieurs injections au cours d'une même consultation, il est préférable de changer de membre pour I'injection de chaque vaccin. Si cela n'est pas possible, les injections dans un même membre devraient être données à une distance d'au moins $2 \mathrm{~cm}$ l'une de l'autre. On doit utiliser un nouveau dispositif d'administration (aiguille et seringue) pour chaque injection.

Il y a un chevauchement considérable des groupes cibles pour lesquels le vaccin contre l'influenza et le vaccin polysaccharidique contre le pneumocoque sont recommandés. Lorsqu'ils administrent le vaccin contre l'influenza, les professionnels de la santé devraient en profiter pour vacciner contre le pneumocoque les personnes admissibles, conformément au Guide canadien d'immunisation ${ }^{(71)}$.

\section{IV.6 EFFETS SECONDAIRES}

VTI

Le vaccin antigrippal inactivé ne peut pas causer l'influenza, car il ne contient pas de virus vivant. Dans le cas des vaccins administrés par voie intramusculaire, il se produit souvent chez les adultes une douleur au point d'injection pouvant persister jusqu'à deux jours, mais elle perturbe rarement les activités quotidiennes. On n'a observé aucune augmentation des cas de fièvre ni d'autres symptômes généraux chez les adultes en bonne santé ayant reçu le VTI par rapport à ceux qui avaient reçu un placebo.

Le VTI est sûr et bien toléré chez les enfants en santé. Des réactions locales bénignes, surtout une sensibilité au point d'injection, sont observées chez au plus $7 \%$ des enfants en santé de moins de 3 ans. Une fièvre peut se produire après la vaccination chez un faible pourcentage ( $\leq 12 \%)$ d'enfants vaccinés entre 1 et 5 ans.

Les formulations multi doses du vaccin antigrippal inactivé qui sont homologuées au Canada (Fluviral ${ }^{\circledR}$, Vaxigrip ${ }^{\circledR}$ et Fluzone ${ }^{\circledR}$ ) contiennent d'infimes quantités de thimérosal, qui est utilisé comme agent de conservation ${ }^{(72)(73)}$. De vastes études de cohortes faites à partir de bases de données sur la santé ont montré qu'il n'existe aucune association entre I'administration durant l'enfance de vaccins contenant du thimérosal et des effets neuro-développementaux, notamment les troubles du spectre autistique ${ }^{(74)}$. Malgré l'absence de données indiquant l'existence d'un risque associé à un tel vaccin, les fabricants de vaccins antigrippaux au Canada s'efforcent actuellement de produire et de commercialiser des vaccins antigrippaux sans thimérosal. Toutes les formulations uni-doses du VTI (et du WAI) sont exemptes de thimérosal.

Durant la saison grippale 2000-2001, on a reçu un nombre accru de rapports de cas de syndrome oculo-respiratoire (SOR) après I'administration du VTI. La définition de cas de SOR est la suivante : apparition d'une rougeur oculaire bilatérale et/ou de symptômes respiratoires (toux, respiration sifflante, oppression thoracique, difficulté à respirer ou à avaler, voix rauque ou mal de gorge) et/ou œdème facial survenant dans les 24 heures qui suivent la vaccination contre l'influenza ${ }^{(75)}$. Depuis, un moins grand nombre de cas ont été signalés. Le mécanisme physiopathologique qui sous-tend le SOR n'a pas été élucidé, mais est considéré comme distinct de l'allergie provoquée par la médiation des lgE. 
Les personnes revaccinées chez lesquelles il y a récidive du SOR ne connaîtront pas nécessairement d'autres épisodes de SOR lors d'une vaccination ultérieure. Rien n'indique dans les données sur les effets secondaires importants sur le plan clinique qu'il faille accorder la préférence à un vaccin plutôt qu'à un autre lorsqu'on revaccine une personne qui a déjà présenté un SOR. Pour plus de détails sur le SOR, se reporter au Guide canadien d'immunisation et au RMTC 2005, vol. 31 à l'adresse http://www.phac-aspc. gc.ca/publicat/ccdr-rmtc/05vol31/rm3121a-fra.php.

Le VTI contenant I'adjuvant MF59 $\left(\right.$ Fluad $^{\circledR}$ ) peut occasionner des réactions locales (douleur, érythème et induration) de façon significativement plus fréquente que les vaccins de comparaison sans adjuvant, mais ces réactions sont bénignes et temporaires. Les réactions générales (myalgie, céphalée, fatigue et malaise) associées à Fluad ${ }^{\circledR}$ surviennent à une fréquence comparable ou supérieure à celles observées avec les vaccins sans adjuvant et sont considérées comme d'intensité légère à modérée, et passagères.

L'incidence des effets locaux et généraux est similaire lorsque Fluad ${ }^{\circledR}$ est ré-administré au cours des saisons grippales subséquentes. Les effets secondaires graves sont rares et leur incidence est comparable après l'administration de Fluad $^{\circledR}$ et des vaccins de comparaison ${ }^{(19)}$.

Le VTI administré par voie intradermique (IntanzaMD) cause des réactions au point d'injection plus fréquentes et plus marquées (érythème, œdème, induration et prurit) que les vaccins administrés par voie IM, mais ces réactions sont en général bénignes et disparaissent spontanément en quelques jours. Les réactions générales associées à IntanzaMD sont similaires à celles qu'entraîne un vaccin administré par voie IM, sauf en ce qui concerne la myalgie, qui est moins fréquente avec IntanzaMD. Pour plus de détails, consulter l'addendum à la déclaration du CCNI sur IntanzaMD au : http://www.phac-aspc.gc.ca/publicat/ ccdr-rmtc/11vol37/acs-dcc-4/index-fra.php ${ }^{(17)}$.

\section{VVAI}

Le WAI (FluMist ${ }^{\circledR}$ ) est constitué de virus atténués qui ne peuvent se répliquer qu'à la température qui règne dans la muqueuse nasale. Les effets secondaires qu'éprouvent le plus souvent les personnes ayant reçu le WAI sont la congestion nasale et l'écoulement nasal. Dans une vaste étude sur l'efficacité potentielle du WAI, la respiration sifflante était plus fréquente après le WAI qu'après le VTI uniquement dans le groupe des enfants de moins de 24 mois $^{(18)}$.
Des études sur FluMist ${ }^{\circledR}$ ont montré que le virus vaccinal peut être récupéré par écouvillonnage nasal chez les enfants et les adultes après la vaccination (excrétion du virus). La fréquence de l'excrétion diminue avec l'âge et avec le temps écoulé depuis la vaccination. L'excrétion virale est généralement insuffisante pour permettre la transmission de l'infection, bien qu'on ait observé de rares cas de transmission de virus vaccinaux excrétés d'une personne vaccinée à une autre non vaccinée. Pour des renseignements plus détaillés sur le WAl et l'excrétion virale, prière de consulter la déclaration complémentaire sur FluMist ${ }^{\circledR}$ du CCNI au : http://www.phac-aspc.gc.ca/ publicat/ccdr-rmtc/11vol37/acs-dcc-7/index-fra.php ${ }^{(18)}$.

\section{Autres considérations concernant l'innocuité du vaccin}

Les réactions allergiques au vaccin antigrippal sont rares et résultent d'une hypersensibilité à certains composants du vaccin. Veuillez consulter le Guide canadien d'immunisation ${ }^{(71)}$ pour obtenir plus de détails sur l'administration du vaccin et la prise en charge des effets secondaires, y compris l'anaphylaxie.

Dans une recension d'études effectuées entre 1976 et 2005, I'Institute of Medicine des États-Unis a conclu que le vaccin contre l'influenza d'origine porcine de 1976 était associé à une élévation du risque de syndrome de Guillain-Barré (SGB). Les données n'étaient pas suffisantes cependant pour confirmer ou infirmer l'existence d'une relation causale entre le SGB chez les adultes et la vaccination contre l'influenza saisonnière ${ }^{(75)}$. Des études plus récentes semblent indiquer que le risque absolu de SGB durant la période qui suit la vaccination contre la grippe saisonnière et contre le virus $A(H 1 N 1) p d m 09$ est d'environ un cas en excès pour 1 million de vaccins ${ }^{(77)(78)}$. II faut soupeser le risque de SGB associé à la vaccination antigrippale et le risque de SGB associé à l'infection grippale elle-même ${ }^{(79)-(83)}$.

\section{IV.7 CONTRE-INDICATIONS ET PRÉCAUTIONS}

\section{IV.7.1 Contre-indications}

Le vaccin contre l'influenza ne devrait pas être administré aux :

- personnes qui ont déjà présenté une réaction anaphylactique à une dose antérieure; 
- personnes qui ont déjà présenté une réaction anaphylactique à l'un ou l'autre des composants du vaccin, sauf une allergie aux œufs (voir section IV.3.3.)

Pour plus d'information sur l'innocuité du vaccin et I'anaphylaxie, prière de se reporter au Guide canadien d'immunisation au : http://www.phac-aspc.gc.ca/publicat/ cig-gci/index-fra.php.

On ignore s'il existe une association causale entre la vaccination antigrippale et le risque accru de récidive du SGB chez les personnes ayant des antécédents de cette maladie, peu importe la cause. II semble prudent pour le moment d'éviter de vacciner contre l'influenza les personnes qui ont déjà présenté un SGB dans les six semaines suivant une vaccination antérieure.

\section{Autres contre-indications concernant le VVAI (FluMist ${ }^{\circledR}$ )}

FluMist ${ }^{\circledR}$ ne devrait pas être administré aux :

- Enfants de moins de 24 mois en raison du risque accru de respiration sifflante.

- Sujets atteints d'asthme grave (c.-à-d. qui reçoivent actuellement une glucocorticothérapie orale ou des doses élevées de glucocorticoïdes en inhalation ou présentent une respiration sifflante active) ni à ceux ayant une respiration sifflante qui a nécessité une intervention médicale au cours des 7 jours précédant la vaccination.

- Enfants et adolescents (2 à 17 ans) qui prennent actuellement de l'aspirine ou un traitement contenant de l'aspirine en raison de l'association du syndrome de Reye à l'aspirine et à l'infection par le virus de la grippe de type sauvage. Il est recommandé de ne pas utiliser de médicaments contenant de l'aspirine chez les enfants de moins de 18 ans pendant quatre semaines après I'administration de FluMist ${ }^{\circledR}$.

- Femmes enceintes, parce qu'il s'agit d'un vaccin à virus vivant atténué et qu'on ne dispose pas pour le moment de suffisamment de données quant à son innocuité. Il n'est toutefois pas contre-indiqué chez les femmes qui allaitent.

- Personnes immunodéprimées suite à une maladie sous-jacente ou à un traitement, car le vaccin contient le virus vivant atténué.

\section{IV.7.2 Précautions}

Avant d'administrer le vaccin contre l'influenza, il importe de tenir compte des problèmes possibles, notamment les réactions allergiques à des doses antérieures du vaccin, le syndrome oculo-respiratoire (SOR), une maladie fébrile aiguë et les interactions médicamenteuses.
Il faudrait demander à un expert d'évaluer les risques et les avantages de la vaccination dans le cas des personnes qui ont déjà manifesté des symptômes graves des voies respiratoires inférieures (respiration sifflante, oppression thoracique, difficulté à respirer) dans les 24 heures suivant la vaccination antigrippale, une réaction allergique apparente au vaccin ou tout autre symptôme (p. ex. constriction de la gorge, dysphagie) suscitant des craintes quant aux dangers d'une revaccination. Ces conseils peuvent être fournis par les médecins hygiénistes locaux ou d'autres experts en maladies infectieuses, en allergologie/immunologie ou en santé publique.

Compte tenu de la morbidité et de la mortalité considérable associée à l'influenza, un diagnostic d'allergie au vaccin antigrippal ne devrait être établi qu'après confirmation par un spécialiste en allergologie/immunologie (ce qui peut nécessiter des tests cutanés). Les personnes qui souffrent d'une allergie à des substances qui ne sont pas contenues dans le vaccin contre l'influenza ne courent pas un plus grand risque d'allergie au vaccin antigrippal.

Les sujets qui ont souffert d'un SOR, notamment ceux qui ont présenté des symptômes graves (rougeur bilatérale des yeux, toux, mal de gorge, voix rauque, œdème facial), mais sans symptômes des voies respiratoires inférieures, peuvent être revaccinés sans danger. Les personnes atteintes d'un SOR accompagné de symptômes des voies respiratoires inférieures devraient être évaluées par un expert (pour plus d'information sur le SOR, consulter le RMTC 2005, vol. 31 à l'adresse http://www.phac-aspc.gc. ca/publicat/ccdr-rmtc/05vol31/dr3121a-fra.php). Les professionnels de la santé qui ne sont pas sûrs si une personne a déjà présenté un SOR ou a eu une réaction d'hypersensibilité provoquée par la médiation des lgE devraient demander conseil.

Les personnes atteintes d'une maladie fébrile aiguë grave devraient habituellement attendre avant de se faire vacciner que leurs symptômes se soient atténués. Celles qui souffrent d'une maladie fébrile bénigne (p. ex. infection bénigne des voies respiratoires supérieures) peuvent recevoir le vaccin. On ne devrait pas perdre l'occasion d'immuniser une personne à cause d'un report indu de la vaccination.

Bien que le vaccin contre la grippe puisse inhiber la clairance de la warfarine et de la théophylline, des études cliniques n'ont pas révélé l'existence d'un quelconque effet secondaire attribuable à ces médicaments chez les personnes ayant reçu le vaccin antigrippal. 


\section{Autres précautions concernant le VVAl (FluMist ${ }^{\circledR}$ )}

En raison du risque théorique de transmission, les personnes vaccinées doivent tenter d'éviter tout contact étroit avec des personnes gravement immunodéprimées (p. ex. les receveurs de greffe de moelle osseuse qui doivent être maintenus en isolement).
Il est aussi recommandé d'attendre 48 heures après l'arrêt du traitement par des antiviraux contre l'influenza (l'oseltamivir et le zanamivir) avant d'administrer FluMist ${ }^{\oplus}$ et $d^{\prime}$ attendre deux semaines après la vaccination par FluMist ${ }^{\circledR}$ avant d'administrer des antiviraux contre I'influenza, à moins que cela ne soit indiqué sur le plan médical. Si des antiviraux sont administrés pendant cette période (entre 48 heures avant I'administration de FluMist ${ }^{\circledR}$ et deux semaines après), il faut envisager une revaccination au moins 48 heures après l'arrêt du traitement antiviral.

\section{Recommandations relatives à la vaccination antigrippale pour la saison 2012-2013}

\section{V.1 CONSIDÉRATIONS GÉNÉRALES}

Les dispensateurs de soins pourront offrir le vaccin contre l'influenza saisonnière dès qu'il sera disponible, étant donné que l'activité grippale saisonnière peut commencer dès le début de novembre dans I'hémisphère Nord. Les décisions concernant le moment exact de la vaccination dans un endroit ou une région géographique donné devraient être prises en fonction des facteurs épidémiologiques locaux (activité grippale, moment et intensité), des moments opportuns pour la vaccination ainsi que des considérations liées aux programmes. Pour obtenir d'autres conseils concernant le moment indiqué pour les programmes de vaccination antigrippal, on peut consulter le personnel local de la santé publique. Même s'il est préférable de donner le vaccin avant le début de la saison grippale, on peut quand même l'administrer jusqu'à la fin de la saison. Les travailleurs de la santé (TS) doivent profiter de toutes les occasions qui se présentent pour administrer le vaccin contre l'influenza aux personnes à risque qui n'ont pas été vaccinées pendant la saison en cours, même après l'observation d'une activité grippale dans la collectivité.

Les risques et avantages de la vaccination antigrippale devraient être abordés avant la vaccination, de même que les risques associés au fait de ne pas recevoir le vaccin.

\section{V.2 PERSONNES POUR QUI LE VACCIN EST RECOMMANDÉ}

Les vaccins antigrippaux actuels homologués au Canada sont immunogènes, sûrs et comportent peu d'effets secondaires. Le vaccin contre l'influenza peut être administré à toutes personnes de 6 mois ou plus pour laquelle il n'existe pas de contre-indications.

Pour que les programmes de vaccination puissent réduire la morbidité et la mortalité associées à l'influenza, ils doivent cibler les personnes qui présentent un risque élevé de complications grippales, celles qui pourraient leur transmettre la grippe et celles qui fournissent des services communautaires essentiels (voir le tableau 4).

Ces personnes demeurent la cible prioritaire des programmes de vaccination antigrippale au Canada. Toutefois, l'influenza saisonnière qui frappe les personnes qui ne sont pas nécessairement considérées comme à risque élevé de complications (personnes en bonne santé âgées de 5 à 64 ans) entraîne aussi une morbidité et des coûts sociaux importants. Le CCNI encourage donc également tous les Canadiens à se faire vacciner contre l'influenza.

Un examen complet par le CCNI des données probantes sur les personnes de 5 à 64 ans est prévu, et les recommandations du CCNI pour la vaccination antigrippale saisonnière seront communiquées au terme de cet examen. 


\section{TABLEAU 4 : Personnes qui devraient recevoir le vaccin antigrippal pour la saison 2012-2013*}

\section{Personnes qui courent un risque élevé de complications liées à l'influenza ou qui risquent fort d'être hospitalisées}

- Adultes (y compris les femmes enceintes) et enfants atteints d'une des affections chroniques suivantes :

- maladies cardiaques ou pulmonaires (notamment dysplasie broncho-pulmonaire, fibrose kystique et asthme);

- diabète sucré ou autres maladies métaboliques;

- cancer, déficits immunitaires (résultant d'une maladie sous-jacente ou d'un traitement);

- néphropathie;

- anémie ou hémoglobinopathies;

- affections qui compromettent l'évacuation des sécrétions respiratoires ou qui sont associées à une augmentation du risque d'aspiration;

- obésité morbide (IMC $\geq 40)$;

- affections qui nécessitent un traitement prolongé par l'AAS (aspirine) chez les enfants et les adolescents.

- Résidents de maisons de soins infirmiers et d'autres établissements de soins de longue durée, quel que soit leur âge.

- Personnes de 65 ans et plus.

- Enfants en bonne santé de 6 à 59 mois ${ }^{\dagger}$.

- Femmes enceintes en santé (le risque d’hospitalisation liée à la grippe augmente avec la durée de la gestation; il est plus élevé au cours du $3^{e}$ trimestre que durant le $2^{\mathrm{e}}$ trimestre).

- Autochtones.

\section{Personnes qui pourraient transmettre la grippe à des sujets à risque élevé}

- Travailleurs de la santé et autres dispensateurs de soins dans des établissements et en milieux communautaires qui, par leurs activités, pourraient transmettre la grippe à des sujets à risque élevé de complications.

- Contacts familiaux (adultes et enfants) de personnes à risque élevé de complications liées à la grippe, que ces dernières aient été vaccinées ou non:

- contacts familiaux de personnes à risque élevé énumérées dans la section ci-dessus;

- contacts familiaux des nourrissons de moins de 6 mois, qui sont à risque élevé de complications grippales, mais pour qui il n'existe actuellement aucun vaccin contre l'influenza;

- membres d'un ménage devant accueillir un nouveau-né durant la saison grippale.

- Personnes qui ont régulièrement soin d'enfants de moins de 59 mois, que ce soit à la maison ou à l'extérieur.

- Personnes qui fournissent des services à des sujets à risque élevé dans un milieu fermé ou relativement fermé (p. ex. équipage de navire).

\section{Autres}

- Personnes qui fournissent des services communautaires essentiels.

- Personnes en contact direct avec de la volaille infectée par le virus de l'influenza aviaire durant les activités d'abattage.

* REMARQUE : On encourage aussi les personnes en bonne santé de 5 à 64 ans pour lesquelles il n'y a pas de contre-indications à se faire vacciner contre I'influenza, même si elles n'appartiennent pas à l'un des groupes prioritaires susmentionnés.

† REMARQUE : Les enfants de 24 à 59 mois ainsi que leurs dispensateurs de soins ont été ajoutés à la liste des personnes pour qui le vaccin est recommandé dans la déclaration de 2012-2013. 


\section{V.2.1 Personnes qui courent un risque élevé de complications liées à I'influenza ou qui risquent fort d'être hospitalisées}

- Adultes (y compris les femmes enceintes) et enfants atteints de certaines maladies chroniques.

Un certain nombre d'affections chroniques sont associées à un risque accru de complications liées à la grippe ou pourraient entraîner une exacerbation de la maladie chronique. Citons entre autres les maladies cardiaques ou pulmonaires (notamment la dysplasie broncho-pulmonaire, la fibrose kystique et l'asthme), le diabète ou d'autres maladies métaboliques, le cancer, les déficits immunitaires (résultant d'une maladie sous-jacente ou d'un traitement), les néphropathies, l'anémie et les hémoglobinopathies, de même que les affections qui compromettent l'évacuation des sécrétions respiratoires et sont associées à une augmentation du risque d'aspiration. On a inclus dans cette catégorie les enfants et les adolescents (de 6 mois à 18 ans) atteints de maladies traitées pendant de longues périodes par l'AAS, en raison de la possibilité d'un risque accru de syndrome de Reye associé à l'influenza.

\section{- Obésité morbide -}

Le CCNI reconnaît que l'information sur l'association entre l'obésité et les complications grippales évolue sans cesse et il encourage la réalisation d'autres recherches à ce sujet. Toutefois, en se basant sur les données faisant état d'un risque accru d'hospitalisations et de complications liées à l'influenza tant saisonnière que pandémique, le CCNI recommande d'inclure les personnes souffrant d'obésité morbide (IMC $\geq 40$ ) de même que d'autres affections chroniques ou non, sur la liste des personnes devant être vaccinées en priorité. On peut aussi envisager d'offrir le vaccin aux autres adultes obèses. Le CCNI souligne qu'on ne s'attend pas à ce qu'il soit nécessaire de mesurer le poids ou l'IMC d'une personne pour appliquer cette recommandation. Pour plus de détails sur les données examinées pour étayer cette recommandation, prière de consulter la " Déclaration sur la vaccination antigrippale pour la saison 2011-2012 » à l'adresse: http://www. phac-aspc.gc.ca/publicat/ccdr-rmtc/11vol37/acs-dcc-5/ index-fra.php.

- Résidents de maisons de soins infirmiers et d'autres établissements de soins de longue durée, quel que soit leur âge.

Ces résidents présentent souvent un ou plusieurs problèmes de santé chronique et leur milieu de vie peut être propice à la propagation de la maladie.

\section{- Personnes de 65 ans et plus.}

Le nombre estimatif d'hospitalisations associées à la grippe dans ce groupe d'âge varie de 125 à 228 pour 100000 personnes en santée ${ }^{(84)}$, et les taux de mortalité augmentent avec l'âge ${ }^{(11)}$.

\section{- Tous les enfants de 6 à 59 mois.}

En se fondant sur des données existantes, le CCNI recommande l'inclusion de tous les enfants de 6 à 59 mois parmi les personnes qui doivent recevoir en priorité le vaccin contre l'influenza.

Il s'agit d'une recommandation révisée par rapport à la déclaration de 2011-2012, qui n'incluait que les enfants de 6 à 23 mois. Le CCNI a procédé à un examen du fardeau de la maladie, de l'efficacité réelle et potentielle du vaccin contre l'influenza ainsi que de son immunogénicité et de son innocuité chez les enfants âgés de 24 à 59 mois; le $\mathrm{CCNI}$ ajoute maintenant ce groupe d'âge aux personnes pour lesquelles il est recommandé de recevoir le vaccin antigrippal. Un examen détaillé de l'analyse documentaire a été réalisé par le $\mathrm{CCNI}$ et il est publié dans une annexe distincte.

Pour d'autres détails sur les enfants de 6 à 23 mois, prière de se reporter à la "Déclaration sur la vaccination antigrippale pour la saison 2011-2012 » à l'adresse http://www.phac-aspc.gc.ca/publicat/ccdr-rmtc/11vol37/ acs-dcc-5/index-fra.php.

\section{- Femmes enceintes.}

Le CCNI recommande l'inclusion de toutes les femmes enceintes, quel que soit le stade de la grossesse, sur la liste des personnes devant recevoir le vaccin en priorité, en raison du risque élevé de morbidité associée à l'influenza chez les femmes enceintes ${ }^{(85)-(89)}$, des preuves d'issue néonatale défavorable associée à l'hospitalisation pour une maladie respiratoire ou l'influenza chez la mère durant la grossesse ${ }^{(90)-(93)}$. Des preuves démontrent que la vaccination des femmes enceintes protège les nouveaunés contre l'influenza et les hospitalisations associées à I'influenza ${ }^{(94)-(97)}$ et qu'il est moins probable que les enfants nés au cours de la saison grippale de mères vaccinées soient prématurés, petits pour leur âge gestationnel et $d^{\prime} u n$ faible poids ${ }^{(98)-(101)}$. Une publication récente appui cette hypothèse que les enfants sont protégés par un transfert transplacentaire des anticorps de la mère vaccinée ${ }^{(102)}$. Omer et coll. ont récemment publié une évaluation des preuves des bienfaits de la vaccination antigrippale maternelle pour la mère et pour l'enfant ${ }^{(103)}$. 
L'innocuité du vaccin antigrippal au cours de la grossesse a récemment été examiné(104). Des études actives de vaccination antigrippale durant la grossesse $n$ 'ont pas permis de déceler des problèmes concernant les événements indésirables graves chez la mère ou le fœus après la vaccination antigrippale durant la grossesse ${ }^{(105)}$. Malgré la petite taille cumulative des échantillons de ces études actives portant sur la vaccination antigrippale chez les femmes enceintes, surtout pour le premier trimestre, la surveillance passive n'a pas soulevé de préoccupation sur l'innocuité de vaccin bien que celui-ci soit utilisé au cours

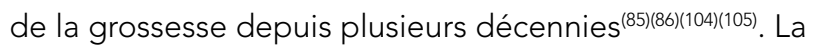
surveillance de I'utilisation du vaccin $\mathrm{pH} 1 \mathrm{~N} 1$, adjuventé ou non, chez plus de 100000 femmes enceintes au Canada et chez plus de 488000 femmes en Europe, n'a révélé aucune préoccupation sur l'innocuité du vaccin ${ }^{(107)(108)}$.

On ne prévoit pas que la réponse anticorps au VTI chez les femmes enceintes soit différente que chez celles non enceintes.

Pour obtenir plus de détails sur la vaccination antigrippale durant la grossesse et pour connaitre les autres données sur lesquelles le CCNI s'est basé pour formuler cette recommandation, le lecteur est prié de consulter la "Déclaration sur la vaccination antigrippale pour la saison 2011-2012 » à l'adresse : http://www.phac-aspc.gc.ca/ publicat/ccdr-rmtc/11vol37/acs-dcc-5/index-fra.php.

- Autochtones - S'appuyant sur le corpus de données indiquant que le taux d'hospitalisation et de mortalité associées à la grippe est plus élevé chez les Autochtones, le CCNI recommande l'inclusion des Autochtones parmi les groupes devant recevoir en priorité le vaccin contre l'influenza.

L'appartenance à la population autochtone est depuis longtemps associée à un risque accru de complications de la grippe, y compris de décès ${ }^{(109)(10)}$. Un constat similaire a été observé durant la pandémie de l'influenza A (H1N1) de 2009 : les populations autochtones du Canada, de l'Australie, de la Nouvelle-Zélande et des États-Unis (É.-U.) ont présenté un taux d'hospitalisation et de mortalité trois à six fois plus élevé que celui de l'ensemble de la population ${ }^{(111)(112)}$.

Certains pensent que le risque accru de grippe grave parmi la population autochtone est dû à de multiples facteurs : forte prévalence de maladies chroniques (comme le diabète, les maladies pulmonaires chroniques et l'insuffisance rénale terminale) $)^{(12)}$, obésité, délais d'accès aux soins de santé et plus grande vulnérabilité aux maladies en raison de logements insalubres et surpeuplés ${ }^{(113)-(115)}$. La recherche sur le mécanisme biologique sous-jacent de la maladie grave chez les Autochtones a donné lieu à certaines hypothèses mais n'a abouti à rien de concluant ${ }^{(116)(117)}$.

Pour plus de détails sur les données dont s'est inspiré le CCNI pour formuler cette recommandation, prière de consulter la " Déclaration sur la vaccination antigrippale pour la saison 2011-2012 » à l'adresse http://www.phacaspc.gc.ca/publicat/ccdr-rmtc/11vol37/acs-dcc-5/indexfra.php

\section{V.2.2 Personnes susceptibles de transmettre la grippe à des sujets à risque élevé de complications grippales ou d'hospitalisation}

Les personnes qui pourraient transmettre la grippe à des sujets à risque élevé devraient être vaccinées tous les ans, que ces sujets aient été vaccinés ou non. En plus de diminuer leur propre risque de contracter la grippe, la vaccination des dispensateurs de soins de santé réduit le risque de décès et d'autres complications graves chez les patients dont ils prennent soin ${ }^{(118)-(124)}$. La vaccination des dispensateurs de soins de santé et des résidents est associée à une diminution du risque d'éclosion de SG ${ }^{(125)}$. Les personnes qui sont les plus susceptibles de transmettre la grippe à ceux qui risquent de souffrir de complications ou d'être hospitalisés en raison de la grippe sont les suivantes :

- Dispensateurs de soins de santé et d'autres soins dans des établissements et en milieux communautaires.

Ce groupe comprend les visiteurs réguliers, le personnel d'urgence, les personnes qui ont des contacts avec des sujets vivant en établissement de soins de longue durée ou dans des résidences, les personnes qui dispensent des soins à domicile à des sujets appartenant à un groupe à risque élevé et les étudiants des services de santé connexes.

- Contacts familiaux (adultes et enfants) des personnes à risque élevé de complications de la grippe, que ces dernières aient été vaccinées ou non.

Ce groupe comprend les contacts familiaux des personnes à risque élevé de complications ou d'hospitalisation liées à la grippe qui ont été déjà mentionnés, les contacts familiaux des nourrissons de moins de 6 mois (qui sont à risque élevé de complications grippales, mais pour lesquels aucun vaccin contre l'influenza n'a été approuvé) et les membres d'un ménage devant accueillir un nouveau-né durant la saison grippale. 
- Personnes qui ont régulièrement soin d'enfants de moins de 59 mois, que ce soit à la maison ou à l'extérieur.

- Personnes qui fournissent des services à des sujets à risque élevé dans un milieu fermé ou relativement fermé (p. ex. équipage de navire).

\section{V.2.3 Autres}

\section{- Personnes qui fournissent des services} communautaires essentiels.

On devrait encourager la vaccination de ces personnes afin que les services et les activités courantes soient le moins perturbé possible durant les épidémies annuelles. Les employeurs et leurs employés devraient envisager la vaccination annuelle, car il a été établi qu'elle contribuait à réduire l'absentéisme dû aux maladies respiratoires et à d'autres maladies.

- Personnes en contact direct avec de la volaille infectée par le virus de l'influenza aviaire durant les activités d'abattage.

Ces personnes peuvent courir un plus grand risque de contracter l'influenza aviaire en raison de leur exposition au virus durant l'opération d'abattage ${ }^{(126-129)}$. Dans certains pays ${ }^{(130)}$ et certaines provinces, on recommande la vaccination antigrippale annuelle des travailleurs de ce secteur en invoquant le fait qu'en théorie, cette vaccination pourrait prévenir l'infection de ces personnes par des souches virales humaines de l'influenza et ainsi réduire le risque de réassortiment des gènes des virus humain et aviaire advenant une coinfection par le virus de l'influenza aviaire chez ces travailleurs ${ }^{(131)}$. On peut définir le contact direct comme une exposition suffisante à la volaille infectée pour favoriser la transmission du virus de I'influenza aviaire à la personne exposée. Les sujets visés sont ceux qui font l'abattage, ainsi que tous ceux qui sont directement exposés au virus de l'influenza aviaire, notamment les vétérinaires et les inspecteurs. Chez les personnes qui sont vaccinées juste avant d'être exposées à l'influenza aviaire, les anticorps protecteurs contre les souches du virus humain contenues dans le vaccin n'apparaîtront pas avant 14 jours environ. Pour obtenir plus d'information sur les problèmes de santé humaine liés aux éclosions d'influenza aviaire au Canada, on peut consulter les recommandations de l'ASPC à l'adresse suivante: http://www.phac-aspc.gc.ca/publicat/daio-enia/indexfra.php.

\section{V.2.4 Autres commentaires concernant la vaccination contre l'influenza}

\section{- Vaccination des personnes en santé âgées de 5 à 64 ans.}

On encourage toutes personnes âgées de 5 à 64 ans à se faire vacciner, même si elles n'appartiennent pas à l'un des groupes prioritaires susmentionnés. Pour plus d'information sur l'efficacité potentielle et réelle du vaccin, voir la section IV.2.

\section{- Voyageurs}

Le CCNI encourage tous les voyageurs à se faire vacciner contre l'influenza même s'ils ne font pas partie des groupes prioritaires susmentionnés.

Les préparations ou produits vaccinaux formulés expressément pour l'hémisphère Sud ne sont pas disponibles actuellement au Canada, et le degré de concordance entre les composants recommandés du vaccin destiné à l'hémisphère Sud et ceux des produits canadiens disponibles varie. Pour plus de renseignements sur les conseils aux voyageurs concernant la prévention de la grippe, on peut consulter la déclaration du Comité consultatif de la médecine tropicale et de la médecine des voyages (CCMTMV) (http://www.phac-aspc.gc.ca/publicat/ ccdr-rmtc/05pdf/acs-dcc3102.pdf (132).

\section{V.3 CHOIX DU VACCIN}

Étant donné la récente homologation de plusieurs nouveaux vaccins, dont certains conçus pour améliorer l'immunogénicité chez des groupes d'âge particuliers, le choix d'un vaccin n'est plus chose simple.

Le tableau 5 résume les recommandations actuelles du $\mathrm{CCNI}$ concernant le choix d'un vaccin antigrippal pour différents groupes d'âge et groupes à risque. Les paragraphes qui suivent donnent plus de précisions sur ces recommandations ainsi qu'une brève justification pour chacune d'elles. 
TABLEAU 5 : Choix du vaccin antigrippal pour certains groupes d'âge et certains groupes à risque (en l'absence de contre-indications)

\begin{tabular}{|c|c|c|c|c|}
\hline Groupes d'âge & $\begin{array}{l}\text { Types de vaccine } \\
\text { disponibles }\end{array}$ & $\begin{array}{l}\text { Vaccin privilégié } \\
\text { (le cas échéant) } \\
\text { Personnes en bonne } \\
\text { santé }\end{array}$ & $\begin{array}{l}\text { Vaccin privilégié } \\
\text { (le cas échéant) } \\
\text { Personnes souffrant } \\
\text { d'une maladie } \\
\text { chronique }\end{array}$ & Commentaires \\
\hline $\begin{array}{l}\text { Enfants de } \\
6 \text { à } 23 \text { mois }\end{array}$ & VTI & - & - & $\begin{array}{l}\text { Seul le VTI est disponible pour } \\
\text { ce groupe d'âge }\end{array}$ \\
\hline $\begin{array}{l}\text { Enfants de } \\
2 \text { à } 17 \text { ans }\end{array}$ & $\begin{array}{l}\text { VTI } \\
\text { VVAI }\end{array}$ & WAI & Aucune préférence & $\begin{array}{l}\text { Enfants immunodéprimés: } \\
\text { - Le WAI n'est pas recommandé }\end{array}$ \\
\hline $\begin{array}{l}\text { Adultes de } \\
18 \text { à } 59 \text { ans }\end{array}$ & $\begin{array}{l}\text { VTI } \\
\text { VTI-ID }(9 \mu \mathrm{g}) \\
\text { VVAI }\end{array}$ & Aucune préférence & $\begin{array}{l}\text { VTI } \\
\text { VTI-ID }(9 \mu \mathrm{g})^{\dagger}\end{array}$ & $\begin{array}{l}\text { Adultes immunodéprimés: } \\
\text { - Le WAI n'est pas recommandé }\end{array}$ \\
\hline $\begin{array}{l}\text { Adultes de } \\
60 \text { à } 64 \text { ans }\end{array}$ & $\begin{array}{l}\text { VTI } \\
\text { VTI-ID }(15 \mu \mathrm{g})\end{array}$ & Aucune préférence & Aucune préférence & \\
\hline $\begin{array}{l}\text { Adultes de } \\
65 \text { ans et plus }\end{array}$ & $\begin{array}{l}\text { VTI } \\
\text { VTI-ID }(15 \mu \mathrm{g}) \\
\text { VTI avec I'adjuvant } \\
\text { MF59 }\end{array}$ & Aucune préférence & Aucune préférence & \\
\hline Femmes enceintes & $\begin{array}{l}\text { VTI } \\
\text { VTI-ID }(9 \mu \mathrm{g})\end{array}$ & Aucune préférence & Aucune préférence & Le WAI n'est pas recommandé \\
\hline
\end{tabular}

$\mathrm{VTI}=$ vaccin trivalent inactivé contre I'influenza (pour administration IM); VTI-ID = vaccin trivalent inactivé contre I'influenza pour administration intradermique; $\mathrm{VAl}=$ vaccin à virus vivant atténué contre l'influenza

† Avec les adultes immunodéprimés, envisager la présentation à $15 \mu \mathrm{g}$ du VTI-ID.

\section{Enfants de 6 à 23 mois}

Pour le moment, seul le VTI est disponible pour ce groupe d'âge.

\section{Enfants de 2 à 17 ans}

Tant le VTI que le WVI (FluMist ${ }^{\circledR}$ ) peuvent être administrés aux enfants âgés de 2 à 17 ans, qu'ils souffrent ou non d'une maladie chronique.

À la lumière des données sur l'efficacité réelle, sur I'efficacité potentielle et sur l'immunogénicité, le CCNI recommande d'utiliser le WAI chez les enfants et les adolescents en bonne santé âgés de 2 à 17 ans. Les données disponibles indiquent qu'il convient de privilégier le WAI dans cette population. Toutefois, le CCNI reconnaît que d'autres considérations liées aux programmes pourraient avoir une incidence sur la mise en œuvre de cette recommandation dans le cadre des programmes financés par l'État. Si le WAI n'est pas disponible, le VTI devrait être utilisé, car il est sûr, potentiellement et réellement efficace dans ce groupe d'âge.
Le CCNI recommande d'utiliser le WAI chez les enfants de 24 mois et plus souffrant d'une forme d'asthme non grave et stable et chez les enfants souffrant d'affections chroniques (à l'exclusion des affections immunodéprimantes et d'une forme d'asthme grave (la définition ci-dessus)).

D'après les examens réalisés par des experts, le WAI devrait être aussi sûr, immunogène et efficace chez les enfants immunocompétents souffrant d'affections chroniques que chez les enfants en bonne santé. Pour l'instant, dans le cas des enfants atteints de maladies chroniques, les données sont insuffisantes pour recommander le WAI plutôt que le $V_{T}{ }^{(18)}$. Le WAI n'est pas recommandé chez les enfants immunodéprimés ou chez ceux qui souffrent d'asthme grave (c.-à-d. ceux qui reçoivent une glucocorticothérapie à forte dose, orale ou par inhalation, ou qui ont une respiration sifflante active) ni chez ceux ayant une respiration sifflante qui a fait l'objet d'une intervention médicale au cours des 7 jours précédant la vaccination. II peut cependant être administré aux enfants dont l'asthme est bénin et stable. 


\section{Adultes de 18 à 59 ans}

Il y a maintenant sur le marché trois types de vaccins pour les adultes âgés de 18 à 59 ans : le VTI, le VTI administré par voie intradermique (VTI-ID) et le WVI.

Pour les adultes en bonne santé de ce groupe d'âge, le CCNI considère que I'un ou l'autre des trois types de vaccin constitue un choix acceptable (à moins de contre-indications) et, par conséquent, n'en privilégie aucun. Les données des essais cliniques ont montré que le VTI-ID (9 $\mu \mathrm{g} / \mathrm{souche})$ est non inférieur sur le plan statistique au VTI (Vaxigrip $\left.{ }^{\circledR}\right)$ pour chacune de trois souches virales évaluées ${ }^{(17)}$. Certaines données semblent indiquer que le VTI serait plus efficace que le VAI chez les adultes en bonne santé, mais les études ne sont pas unanimes sur ce point ${ }^{(18)}$.

En ce qui concerne les adultes de ce groupe d'âge souffrant de maladies chroniques, on peut utiliser le VTI ou le VTI-ID. Les données sur I'emploi du VTI-ID parmi cette population sont limitées toutefois, elles semblent indiquer que le VTI-ID est sans danger et au moins aussi immunogène que le VTI chez les personnes hypo-réactives au vaccin atteintes d'une maladie chronique ${ }^{(17)}$. Si on choisit d'administrer le VTI-ID à des adultes immunodéprimés, il est préférable d'opter pour la présentation à $15 \mu \mathrm{g}$ afin d'améliorer la réponse immunitaire. Pour le moment, le CCNI conclut qu'il ne dispose pas de suffisamment de données pour recommander l'emploi du WAI chez les adultes souffrant de maladies chroniques, surtout si l'on tient compte du fait que, selon certaines études, le VTI assurerait une meilleure réponse immunitaire dans ce groupe d'âge ${ }^{(18)}$. Le WAI n'est pas recommandé pour les adultes immunodéprimés.

Pour obtenir des précisions concernant les travailleurs de la santé, le lecteur doit se reporter à la section VI, ci-dessous.

\section{Adultes de 60 à 64 ans}

Les vaccins disponibles pour les adultes de 60 à 64 ans, souffrant ou non d'une maladie chronique, sont le VTI et le VTI-ID (15 $\mu \mathrm{g} /$ souche).

Le CCNI a conclu qu'il ne dispose pas de suffisamment de données pour privilégier l'emploi du VTI par rapport au VTI-ID, ou l'inverse, dans ce groupe d'âge, car il n'y a pas d'étude portant sur l'efficacité du VTI-ID. Les données de deux essais cliniques auprès d'adultes de 60 ans et plus semblent indiquer que la réponse immunitaire au VTI-ID est statistiquement supérieure à celle qu'induit le VTI
(Vaxigrip ${ }^{\circledR}$ ), bien que l'importance clinique des différences observées reste à être démontrée ${ }^{(17)}$. Pour en savoir davantage, veuillez consulter l'addendum du CCNI relatif au vaccin IntanzaMD à l'adresse suivante : http://www. phac-aspc.gc.ca/publicat/ccdr-rmtc/11vol37/acs-dcc-4/ index-fra.php .

\section{Adultes de 65 ans et plus}

Trois types de vaccin sont disponibles pour les adultes âgés de 65 ans et plus : le VTI, le VTI-ID (15 $\mu \mathrm{g} / \mathrm{souche)}$ et le VTI contenant I'adjuvant MF59.

Pour le moment, le CCNI conclut qu'il ne dispose pas de suffisamment de données pour recommander l'emploi de I'un plutôt que l'autre de ces vaccins chez les adultes de 65 ans et plus ${ }^{(17)(19)}$.

Aucune étude n'a été publiée sur l'efficacité du VTI-ID ou celle du VTI contenant l'adjuvant MF59. Toutefois, selon les quelques études d'observation qui ont été effectuées, il semble que le risque d'hospitalisation en raison de la grippe et de ses complications pour les personnes âgées soit moindre chez les sujets ayant reçu Fluad ${ }^{\circledR}$ que chez ceux qui n'ont pas été vaccinés ou ceux qui ont reçu un vaccin sous-unitaire sans adjuvant. Ces études comportent cependant des limites méthodologiques importantes, qui compliquent leur interprétation ${ }^{(19)}$.

Des essais comparatifs randomisés ont montré que, chez les adultes de 65 ans et plus, Fluad ${ }^{\circledR}$ entraînait une immunogénicité et une réactivité croisée supérieures à celles induites par les vaccins sous-unitaires sans adjuvant et des résultats similaires mais moins constants pour ce qui est de l'amélioration de la réponse immunitaire comparativement au vaccin à virion fragmenté(19). Le produit intradermique, Intanza ${ }^{\mathrm{MD}}$ a démontré qu'il déclenche une réponse immunitaire non-inférieure au VTI, avec ou sans adjuvant, lorsque administré par voie intramusculaire; on peut prévoir une variation des résultats selon la méthode sérologique utilisée $e^{(17)(133)}$.

Les données de deux essais cliniques regroupant plus de 4800 participants de 60 ans ou plus ont montré que la réponse immunitaire produite par Intanza ${ }^{\mathrm{MD}}$ était statistiquement supérieure à celle induite par Vaxigrip ${ }^{\circledR}$, même si les différences dans les taux de séroprotection étaient faibles. La pertinence clinique de ces résultats pour le VTI-ID et le VTI contenant I'adjuvant MF59, en ce qui concerne la protection contre l'infection grippale confirmée en laboratoire, est inconnue. 


\section{Femmes enceintes}

Tant le VTI que le VTI-ID $(9 \mu \mathrm{g})$ est disponible pour les femmes enceintes. Le CCNI considère que les deux types de vaccins sont acceptables. Étant donné du peu de données disponibles sur l'innocuité à ce moment, le VAI, qui est un vaccin à virus vivant atténué, ne devrait pas être administré aux femmes enceintes mais on peut l'administrer aux femmes qui allaitent.

\section{Immunisation des travailleurs de la santé}

La vaccination contre l'influenza apporte des bienfaits tant aux travailleurs de la santé (TS) qu'aux patients dont ils prennent soin. Le CCNI estime que l'administration du vaccin antigrippal aux TS qui ont des contacts directs avec les patients constitue un élément essentiel des normes de conduite pour la protection des patients. Pour les besoins du présent document, un TS est une personne qui dispense des soins directs aux patients ou des services de santé indirects. Le terme " soins directs aux patients » renvoie aux activités au cours desquelles la transmission de la grippe entre les TS et les patients est possible.

La transmission de la grippe entre des TS infectés et leurs patients vulnérables est à l'origine d'une morbidité et d'une mortalité importante. Des essais cliniques randomisés menés dans des établissements gériatriques de soins de longue durée ont démontré que la vaccination des TS est associée à un déclin de la morbidité (119)(122)(134) et de la mortalité(118)(119(121)(122)(134) chez les résidents. Par conséquent, les TS qui ont des contacts directs avec des patients devraient considérer qu'il leur incombe de se faire vacciner chaque année contre l'influenza.
Le CCNI recommande d'utiliser le VTI plutôt que le WAI dans le cas d'un TS qui soigne des patients immunodéprimés, à moins que le TS n'accepte de recevoir que le WAI. Un TS ou toute autre personne qui prend soin de patients gravement immunodéprimés (c.-à-d. hospitalisés et devant être traités dans un milieu protégé) et qui reçoit le WAI doit attendre deux semaines après l'administration du vaccin avant de recommencer à dispenser des soins à ces patients.

Les TS qui ont des contacts directs avec des patients devraient considérer qu'il leur incombe de fournir des soins de qualité supérieure notamment une vaccination antigrippale annuelle. En l'absence de contre-indication, les TS ayant des contacts directs avec les patients qui refusent de se faire vacciner contre l'influenza accusent un manquement à leur responsabilité de soins aux patients.

Si l'on veut protéger les patients vulnérables durant les éclosions d'influenza, il faut empêcher les TS atteints de grippe confirmée ou présumée, ainsi que les TS non vaccinés qui ne reçoivent pas de prophylaxie antivirale, d'avoir des contacts directs avec les patients. Les organisations de soins de santé devraient avoir en place des politiques à cet égard. 


\section{Tableaux}

\section{TABLEAU 6 : Degrés de preuve selon la méthodologie des études}

\begin{tabular}{|c|c|}
\hline I & Données probantes provenant d'un ou de plusieurs essais cliniques comparatifs randomisés. \\
\hline II-1 & Données probantes provenant d'un ou de plusieurs essais cliniques comparatifs sans randomisation. \\
\hline II-2 & $\begin{array}{l}\text { Données probantes provenant d'études analytiques de cohortes ou cas-témoins, de préférence de plus d'un centre ou groupe } \\
\text { de recherche utilisant des indicateurs cliniques de résultats de l'efficacité d'un vaccin. }\end{array}$ \\
\hline II-3 & $\begin{array}{l}\text { Données probantes provenant de multiples études de séries chronologiques avec ou sans intervention. Les résultats spectacu- } \\
\text { laires obtenus dans un contexte non contrôlé (comme les résultats de l'introduction de la pénicilline dans les années 1940) } \\
\text { pourraient aussi être considérés comme faisant partie de ce type de données probantes. }\end{array}$ \\
\hline III & $\begin{array}{l}\text { Opinions d'experts respectés se basant sur des expériences cliniques, des études descriptives et des études de cas ou des } \\
\text { rapports de comités d'experts. }\end{array}$ \\
\hline
\end{tabular}

\section{TABLEAU 7 : Cote de qualité des preuves (validité interne)}

\begin{tabular}{|c|c|}
\hline Bonne & $\begin{array}{l}\text { Étude (notamment les méta-analyses ou les études systématiques) répondant bien à tous les critères propres à la } \\
\text { méthodologie*. }\end{array}$ \\
\hline $\begin{array}{l}\text { Assez } \\
\text { bonne }\end{array}$ & $\begin{array}{l}\text { Étude (notamment les méta-analyses ou les études systématiques) ne répondant pas (ou du moins pas clairement) } \\
\text { à au moins un critère propre à la méthodologie* mais n’ayant pas de « lacune majeure » connue. }\end{array}$ \\
\hline Médiocre & $\begin{array}{l}\text { Étude (notamment les méta-analyses ou les études systématiques) ayant au moins une « lacune majeure » propre à la } \\
\text { méthodologie* ou une accumulation de lacunes moins importantes ne permettant pas aux résultats de l'étude d'alimenter } \\
\text { les recommandations. }\end{array}$ \\
\hline I & $\begin{array}{l}\text { Les données probantes sont insuffisantes (en quantité ou en qualité) pour formuler une recommandation; cependant, } \\
\text { d'autres facteurs peuvent influencer la prise de décision. }\end{array}$ \\
\hline
\end{tabular}

* Les critères généraux propres à la méthodologie sont décrits dans l'article de Harris et al. $2001^{4}$.

\section{TABLEAU 8 : Recommandations du CCNI concernant l'immunisation - Catégories}

\begin{tabular}{|c|c|}
\hline A & Les données probantes sont suffisantes pour recommander l'immunisation. \\
\hline B & Les données probantes sont acceptables pour recommander l'immunisation. \\
\hline C & $\begin{array}{l}\text { Les données probantes existantes sont contradictoires et ne permettent pas de faire une recommandation pour ou contre } \\
\text { l'immunisation; cependant, d'autres facteurs peuvent influencer la prise de décision. }\end{array}$ \\
\hline D & Les données probantes sont acceptables pour déconseiller l'immunisation. \\
\hline E & Les données probantes sont suffisantes pour déconseiller l'immunisation. \\
\hline I & $\begin{array}{l}\text { Les données probantes sont insuffisantes (en quantité ou en qualité) pour formuler une recommandation; cependant, } \\
\text { d'autres facteurs peuvent influencer la prise de décision. }\end{array}$ \\
\hline
\end{tabular}

\footnotetext{
4 Harris RP, Helfand M, Woolf SH, et coll. Current methods of the US Preventive Services Task Force: a review of the process. Am J Prev Med 2001;20:21-35.
} 


\section{Liste des abréviations}

\begin{tabular}{|c|c|c|c|}
\hline$\mu \mathrm{g}$ & microgramme & $\lg E$ & immunoglobuline $\mathrm{E}$ \\
\hline AAA & Amérindiens et Autochtones de l'Alaska & IgG & immunoglobuline G \\
\hline \multirow[t]{2}{*}{ ACIP } & \multirow{2}{*}{$\begin{array}{l}\text { Advisory Committee on Immunization } \\
\text { Practices (É.-U.) }\end{array}$} & IM & intramusculaire \\
\hline & & IMC & indice de masse corporelle \\
\hline ACMTS & $\begin{array}{l}\text { Agence canadienne des médicaments } \\
\text { et des technologies de la santé }\end{array}$ & IMPACT & $\begin{array}{l}\text { Programme de surveillance active des effets } \\
\text { secondaires associés aux vaccins }\end{array}$ \\
\hline \multirow{2}{*}{$\begin{array}{l}\text { AF } \\
\text { AMMI }\end{array}$} & adapté au froid & IVRI & infection des voies respiratoires inférieures \\
\hline & $\begin{array}{l}\text { Association pour la microbiologie médicale } \\
\text { et l'infectiologie Canada }\end{array}$ & IVRS & infection des voies respiratoires supérieures \\
\hline \multirow{2}{*}{$\begin{array}{l}\text { ASPC } \\
\text { AVAO }\end{array}$} & \multirow{2}{*}{$\begin{array}{l}\text { Agence de la santé publique du Canada } \\
\text { année de vie ajustée pour la qualité }\end{array}$} & & Laboratoire national de microbiologie \\
\hline & & $\mathrm{ml}$ & millilitre \\
\hline \multirow{2}{*}{ CCMTMV } & \multirow{2}{*}{$\begin{array}{l}\text { Comité consultatif de la médecine tropicale } \\
\text { et de la médecine des voyages }\end{array}$} & & organisme de gestion des soins \\
\hline & & MRAIM & maladie respiratoire ayant nécessité \\
\hline \multirow{2}{*}{$\begin{array}{l}\mathrm{CCNI} \\
\mathrm{CDC}\end{array}$} & \multirow{2}{*}{$\begin{array}{l}\text { Comité consultatif national de l'immunisation } \\
\text { Centers for Disease Control and Prevention } \\
\text { des États-Unis }\end{array}$} & & \\
\hline & & NE & $\begin{array}{l}\text { neuramınıdase } \\
\text { non-estimé }\end{array}$ \\
\hline \multirow[t]{2}{*}{ CEPCM } & \multirow{2}{*}{$\begin{array}{l}\text { Centre européen de prévention } \\
\text { et de contrôle des maladies }\end{array}$} & OE & oxygénation extracorporelle \\
\hline & & OMA & otite moyenne aiguë \\
\hline CIM & Classification internationale des maladies & OME & otite moyenne avec épanchement \\
\hline CIMRI & $\begin{array}{l}\text { Centre de l'immunisation et des maladies } \\
\text { respiratoires infectieuses }\end{array}$ & OMS & Organisation mondiale de la Santé \\
\hline ECR & $\begin{array}{l}\text { respiratoires intectieuses } \\
\text { essai comparatif randomisé }\end{array}$ & PCSIN & $\begin{array}{l}\text { Programme canadien de surveillance des } \\
\text { infections nosocomiales }\end{array}$ \\
\hline El & écart interquartile & pH1N1 & virus pandémique de l'influenza H1N1 de 2009 \\
\hline EIM & $\begin{array}{l}\text { événement ayant nécessité une } \\
\text { intervention médicale }\end{array}$ & PUVI & $\begin{array}{l}\text { Programme universel de vaccination contre } \\
\text { l'influenza (Ontario) }\end{array}$ \\
\hline ESG & effet secondaire grave & $\mathbf{R}$ & réactogénicité \\
\hline ESLD & établissement de soins de longue durée & R.-U. & Royaume-Uni \\
\hline ESSI & effet secondaire suivant l'immunisation & RC & rapport de cotes \\
\hline É.-U. & États-Unis & RMTC & Relevé des maladies transmissibles au Canada \\
\hline EV & efficacité du vaccin & RR & risque relatif \\
\hline DS & durée du séjour & RTI & ratio des taux d'incidence \\
\hline GT & gastro-intestinal & SD & écart-type \\
\hline GTI & Groupe de travail sur l'influenza & SG & syndrome grippal \\
\hline H & hémagglutinine & SCAIC & $\begin{array}{l}\text { Société canadienne d'allergie et } \\
\text { d'immunologie clinique }\end{array}$ \\
\hline IAV & ction aigue de & & \\
\hline IC & intervalle de confiance & SCSESSI & $\begin{array}{l}\text { Systeme canadien de survellance des effets } \\
\text { secondaires suivant l'immunisation }\end{array}$ \\
\hline 10 & 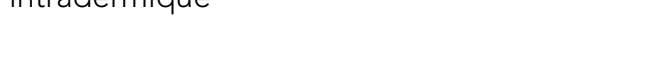 & SGB & syndrome de Guillain-Barré \\
\hline
\end{tabular}


SIP $\quad$ soins intensifs pédiatriques

SOR syndrome oculo-respiratoire

SV $\quad$ service des urgences

TESSy European Surveillance System

TS travailleur de la santé

UFF unité de foyers fluorescents

USI unité de soins intensifs

VAERS Vaccine Adverse Event Reporting System (É.-U.)

VAO vaccin antipoliomyélitique oral

VIH virus de l'immunodéficience humaine

VHB vaccin contre I'hépatite B

VL vente libre

VRS virus respiratoire syncytial

VTI vaccin trivalent inactivé

VTI-ID vaccin trivalent inactivé administré par voie intradermique

VVAI vaccin à virus vivant atténué contre l'influenza 


\section{Références}

(1) Heckler R, Baillot A, Engelmann H, et coll. Crossprotection against homologous drift variants of influenza $A$ and $B$ after vaccination with split vaccine. Intervirology. 2007;50(1):58-62.

(2) Walter EB, Neuzil KM, Zhu Y, et coll. Influenza vaccine immunogenicity in 6- to 23-month-old children: are identical antigens necessary for priming?. Pediatrics. 2006;118(3):e570-8.

(3) Englund JA, Walter EB, Gbadebo A, et coll. Immunization with trivalent inactivated influenza vaccine in partially immunized toddlers. Pediatrics. 2006;118(3):e579-85.

(4) Levandowski RA, Regnery HL, Staton E, et coll. Antibody responses to influenza $B$ viruses in immunologically unprimed children. Pediatrics. 1991;88(5):1031-6.

(5) Levandowski RA, Gross PA, Weksler M, et coll. Cross-reactive antibodies induced by a monovalent influenza B virus vaccine. J Clin Microbiol. 1991;29(7):1530-2.

(6) Influenza. 2008; Disponible au : http://www.who.int/ immunization/topics/influenza/en

(7) World Health Organization. WHO position paper on influenza. Weekly Epidemiological Record. 2002(33):March 62012.

(8) Nguyen-Van-Tam J. Epidemiology of Influenza. In: Nicholson K, Webster R, Hay A, editors. Textbook of Influenza London: Blackwell Science; 1998. p. 181.

(9) Schanzer DL, Langley JM, Tam TW. Hospitalization attributable to influenza and other viral respiratory illnesses in Canadian children. Pediatr Infect Dis J. 2006;25(9):795-800.

(10) Schanzer D, Langley J, Tam T. Role of influenza and other respiratory viruses in admissions of adults to Canadian hospitals. Influenza \& Other Respiratory Viruses. 2008;2(1):1-8.

(11) Schanzer DL, Tam TW, Langley JM, et coll. Influenzaattributable deaths, Canada 1990-1999. Epidemiol Infect. 2007;135(7):1109-16.

(12) Reyes F, Macey JF, Aziz S, et coll. Influenza au Canada: saison 2005-2006. RMTC . 2007;33(3):21-41.
(13) Organisation mondiale de la Santé. Recommandations sur la composition des virus de I'influenza du vaccin pour la saison grippale 20122013 en Amérique du Nord. Disponible (en anglais seulement) au : http://www.who.int/influenza/ vaccines/virus/recommendations/2012_13_north/en/ index.html

(14) Organisation mondiale de la Santé - Interface entre I'homme et l'animal (IHAI. 2012; Disponible au: http://www.who.int/influenza/human_animal_ interface/fr/index.html

(15) Centers for Disease Control and Prevention. Reported human infections with variant influenza viruses in the United States since 2005. 2012; Disponible au : http:// www.cdc.gov/flu/swineflu/variant-cases-us.htm

(16) Centers for Disease Control and Prevention. First H3N2 Variant Virus Infection Reported for 2012. Disponible au : http://www.cdc.gov/flu/spotlights/ h3n2v-variant-utah.htm. Accédé le 18 avril 2012.

(17) Comité consultatif national de l'immunisation. Addendum à la déclaration sur le vaccin inactivé trivalent contre l'influenza saisonnière de 2010-2011. Recommandations concernant l'utilisation du vaccin antigrippal trivalent inactivé intradermique (VTI-ID). RMTC. 2011;37(ACS-4): 6 mars 2012.

(18) Comité consultatif national de l'immunisation. Recommandations relatives à l'utilisation du vaccin antigrippal vivant atténué (FluMist ${ }^{\circledR}$ ) : Déclaration complémentaire sur la vaccination antigrippale pour la saison 2011-2012. RMTC. 2011;37(ACS-7): 6 mars 2012.

(19) Comité consultatif national de l'immunisation. Recommandations relatives au vaccin antigrippal trivalent contenant l'adjuvant MF59 (Fluad ${ }^{\circledR}$ ) : Déclaration supplémentaire sur le vaccin contre la grippe saisonnière de 2011-2012. RMTC. 2011;37(ACS-6): 6 mars 2012.

(20) Langley JM, Faughnan ME, Canadian Task Force on Preventive Health, Care. Prevention of influenza in the general population: recommendation statement from the Canadian Task Force on Preventive Health Care. CMAJ. 2004;171(10):1169-70. 
(21) Jefferson T, Rivetti A, Harnden A, et coll. Vaccines for preventing influenza in healthy children. Cochrane Database Syst Rev. 2008(2):004879.

(22) Negri E, Colombo C, Giordano L, et coll. Influenza vaccine in healthy children: a meta-analysis. Vaccine. 2005;23(22):2851-61.

(23) Manzoli L, Schioppa F, Boccia A, et coll. The efficacy of influenza vaccine for healthy children : a metaanalysis evaluating potential sources of variation in efficacy estimates including study quality. Pediatr Infect Dis J. 2007;26(2):97-106.

(24) Jefferson T, Di Pietrantonj C, Rivetti A, et coll. Vaccines for preventing influenza in healthy adults. Cochrane Database Syst Rev. 2010(7):001269.

(25) Jefferson TO, Rivetti D, Di Pietrantonj C, et coll. Vaccines for preventing influenza in healthy adults. Cochrane Database Syst Rev. 2007;(2)(2):CD001269.

(26) Ohmit SE, Victor JC, Rotthoff JR, et coll. Prevention of antigenically drifted influenza by inactivated and live attenuated vaccines. N Engl J Med. 2006;355(24):2513-22.

(27) Herrera GA, Iwane MK, Cortese M, et coll. Influenza vaccine effectiveness among 50-64-year-old persons during a season of poor antigenic match between vaccine and circulating influenza virus strains: Colorado, United States, 2003-2004. Vaccine. 2007;25(1):154-60.

(28) Govaert TM, Thijs CT, Masurel N, et coll. The efficacy of influenza vaccination in elderly individuals. A randomized double-blind placebo-controlled trial. JAMA. 1994;272(21):1661-5.

(29) Rivetti D, Jefferson T, Thomas R, et coll. Vaccines for preventing influenza in the elderly. Cochrane Database Syst Rev. 2006;3:004876.

(30) Poole PJ, Chacko E, Wood-Baker RW, et coll. Influenza vaccine for patients with chronic obstructive pulmonary disease. Cochrane Database Syst Rev. 2006(1):002733.

(31) Hak E, Buskens E, van Essen GA, et coll. Clinical effectiveness of influenza vaccination in persons younger than 65 years with high-risk medical conditions: the PRISMA study. Arch Intern Med. 2005;165(3):274-80.
(32) Nichol KL, Nordin J, Mullooly J, et coll. Influenza vaccination and reduction in hospitalizations for cardiac disease and stroke among the elderly. N Engl J Med. 2003;348(14):1322-32.

(33) Looijmans-Van den Akker I, Verheij TJ, Buskens E, et coll. Clinical effectiveness of first and repeat influenza vaccination in adult and elderly diabetic patients. Diabetes Care. 2006;29(8):1771-6.

(34) Orenstein EW, De Serres G, Haber MJ, et coll. Methodologic issues regarding the use of three observational study designs to assess influenza vaccine effectiveness. Int J Epidemiol.

2007;36(3):623-31.

(35) Simonsen L. Commentary: Observational studies and the art of accurately measuring influenza vaccine benefits. Int J Epidemiol. 2007;36(3):631-2.

(36) Jackson LA, Jackson ML, Nelson JC, et coll. Evidence of bias in estimates of influenza vaccine effectiveness in seniors. Int J Epidemiol. 2006;35(2):337-44.

(37) Jackson LA, Nelson JC, Benson P, et coll. Functional status is a confounder of the association of influenza vaccine and risk of all cause mortality in seniors. Int J Epidemiol. 2006;35(2):345-52.

(38) Simonsen L, Taylor RJ, Viboud C, et coll. Mortality benefits of influenza vaccination in elderly people: an ongoing controversy. Lancet Infect Dis. 2007;7(10):658-66.

(39) Simonsen L, Viboud C, Taylor RJ. Effectiveness of influenza vaccination. N Engl J Med. 2007;357(26):2729-30.

(40) Thomas PG, Keating R, Hulse-Post DJ, et coll. Cell-mediated protection in influenza infection. Emerg Infect Dis. 2006;12(1):48-54.

(41) Skowronski DM, Tweed SA, De Serres G. Rapid decline of influenza vaccine-induced antibody in the elderly: is it real, or is it relevant? J Infect Dis. 2008;197(4):490-502.

(42) Anema A, Mills E, Montaner J, et coll. Efficacy of influenza vaccination in HIV-positive patients: a systematic review and meta-analysis. HIV Med. 2008;9(1):57-61. 
(43) Cooper C, Hutton B, Fergusson D, et coll. A review of influenza vaccine immunogenicity and efficacy in HIV-infected adults. Can j infect dis med microbiol. 2008;19(6):419-23.

(44) Scharpe J, Evenepoel P, Maes B, et coll. Influenza vaccination is efficacious and safe in renal transplant recipients. Am J Transplant. 2008;8(2):332-7.

(45) Manuel O, Humar A, Chen $\mathrm{MH}$, et coll. Immunogenicity and safety of an intradermal boosting strategy for vaccination against influenza in lung transplant recipients. Am J Transplant. 2007;7(11):2567-72.

(46) Engelhard D, Nagler A, Hardan I, et coll. Antibody response to a two-dose regimen of influenza vaccine in allogeneic T cell-depleted and autologous BMT recipients. Bone Marrow Transplant. 1993;11(1):1-5.

(47) Buxton JA, Skowronski DM, Ng H, et coll. Influenza revaccination of elderly travelers: antibody response to single influenza vaccination and revaccination at 12 weeks. J Infect Dis. 2001;184(2):188-91.

(48) Ljungman P, Nahi H, Linde A. Vaccination of patients with haematological malignancies with one or two doses of influenza vaccine: a randomised study. Br J Haematol. 2005;130(1):96-8.

(49) McElhaney JE, Hooton JW, Hooton N, et coll. Comparison of single versus booster dose of influenza vaccination on humoral and cellular immune responses in older adults. Vaccine. 2005;23(25):3294-300.

(50) Gross PA, Weksler ME, Quinnan GV,Jr, et coll. Immunization of elderly people with two doses of influenza vaccine. J Clin Microbiol. 1987;25(9):1763-5.

(51) Mosca F, Tritto E, Muzzi A, et coll. Molecular and cellular signatures of human vaccine adjuvants. Proc Natl Acad Sci U S A. 2008;105(30):10501-6.

(52) Seubert A, Monaci E, Pizza M, et coll. The adjuvants aluminum hydroxide and MF59 induce monocyte and granulocyte chemoattractants and enhance monocyte differentiation toward dendritic cells. The journal of immunology. 2008;180(8):5402-12.

(53) Calabro S, Tortoli M, Baudner B, et coll. Vaccine adjuvants alum and MF59 induce rapid recruitment of neutrophils and monocytes that participate in antigen transport to draining lymph nodes. Vaccine. 2011;29(9):1812-23.
(54) O'Hagan D, Rappuoli R, De Gregorio E, et coll. MF59 adjuvant: the best insurance against influenza strain diversity. Expert review of vaccines. 2011;10(4):447-62.

(55) Ritzwoller DP, Bridges CB, Shetterly S, et coll. Effectiveness of the 2003-2004 influenza vaccine among children 6 months to 8 years of age, with 1 vs 2 doses. Pediatrics. 2005;116(1):153-9.

(56) Neuzil KM, Jackson LA, Nelson J, et coll. Immunogenicity and reactogenicity of 1 versus 2 doses of trivalent inactivated influenza vaccine in vaccine-naive 5-8-year-old children. J Infect Dis. 2006;194(8):1032-9.

(57) Shuler CM, Iwamoto M, Bridges CB, et coll. Vaccine effectiveness against medically attended, laboratoryconfirmed influenza among children aged 6 to 59 months, 2003-2004. Pediatrics. 2007;119(3):e587-95.

(58) Allison MA, Daley MF, Crane LA, et coll. Influenza vaccine effectiveness in healthy 6 - to 21 -month-old children during the 2003-2004 season. J Pediatr. 2006;149(6):755-62.

(59) Englund JA, Walter EB, Fairchok MP, et coll. A comparison of 2 influenza vaccine schedules in 6- to 23-month-old children. Pediatrics. 2005;115(4):1039-47.

(60) Skowronski DM, Hottes TS, De Serres G, et coll. Influenza B/Victoria antigen induces strong recall of $\mathrm{B} /$ Yamagata but lower B/Victoria response in children primed with two doses of B/Yamagata. Pediatr Infect Dis J. 2011;30(10):833-9.

(61) Skowronski DM, Hottes TS, Chong M, et coll. Randomized controlled trial of dose response to influenza vaccine in children aged 6 to 23 months. Pediatrics. 2011;128(2):e276-89.

(62) Langley JM, Vanderkooi OG, Garfield HA, et coll. Immunogenicity and Safety of 2 Dose Levels of a Thimersol-Free Trivalent Seasonal Influenza Vaccine in Children Aged 6-35 Months: A Randomized, Controlled Trial. J Ped Infect Dis. 2012;1(1):55-8.

(63) James JM, Zeiger RS, Lester MR, et coll. Safe administration of influenza vaccine to patients with egg allergy. J Pediatr. 1998;133(5):624-8.

(64) Li JT, Rank MA, Squillace DL, et coll. Ovalbumin content of influenza vaccines. J Allergy Clin Immunol. 2010;125(6):1412-3. 
(65) Waibel KH, Gomez R. Ovalbumin content in 2009 to 2010 seasonal and H1N1 monovalent influenza vaccines. J Allergy Clin Immunol. 2010;125(3):749; Mar-751.

(66) Gagnon R, Primeau MN, Des Roches A, et coll. Safe vaccination of patients with egg allergy with an adjuvanted pandemic $\mathrm{H} 1 \mathrm{~N} 1$ vaccine. J Allergy Clin Immunol. 2010;126(2):317-23.

(67) La Société canadienne d'allergie et d'immunologie clinique. Déclaration sur l'administration du vaccin H1N1 et le vaccin contre l'influenza saisonnière aux personnes allergiques aux œufs. 2009; Disponible (en anglais seulement) au : http:www.csaci.ca/include/ files/CSACl_-H1N1Statement.pdf

(68) Lum LC, Borja-Tabora CF, Breiman RF, et al. Influenza vaccine concurrently administered with a combination measles, mumps, and rubella vaccine to young children. Vaccine. 2010;28(6):1566-74.

(69) Nolan T, Bernstein DI, Block SL, et al. Safety and immunogenicity of concurrent administration of live attenuated influenza vaccine with measles-mumpsrubella and varicella vaccines to infants 12 to 15 months of age. Pediatrics. 2008;121(3):508-16.

(70) Breiman RF, Brooks WA, Goswami D, et al. A multinational, randomized, placebo-controlled trial to assess the immunogenicity, safety, and tolerability of live attenuated influenza vaccine coadministered with oral poliovirus vaccine in healthy young children. Vaccine. 2009;27(40):5472-9.

(71) Comité consultatif national sur l'immunisation (CCNI). Guide canadien d'immunisation - 7e Édition 2006.

(72) Comité consultatif national sur l'immunisation (CCNI). Déclaration sur le thimérosal. RMTC. 2003;29(ACS-1) (ACS-1):1-12.

(73) Comité consultatif national sur l'immunisation (CCNI). Thimérosal : nouvelle déclaration. Une déclaration d'un comité consultatif (DCC) RMTC. 2007;33(ACS-6):1-13.

(74) Gerber JS, Offit PA. Vaccines and autism: a tale of shifting hypotheses. Clin Infect Dis. 2009;48(4):456-61.

(75) Comité consultatif national sur l'immunisation (CCNI). Déclaration supplémentaire pour la saison grippale 2002-2003 : le point sur le syndrome oculo-respiratoire associé au vaccin antigrippal. RMTC 2002;28(ACS-6):1-8.
(76) Institute of Medicine. Immunization safety review: Influenza vaccines and neurological complications. Washington, D.C.: Institute of Medicine of the National Academies; 2008.

(77) Juurlink DN, Stukel TA, Kwong J, et coll. GuillainBarre syndrome after influenza vaccination in adults: a population-based study. Arch Intern Med. 2006;166(20):2217-21.

(78) Prothro C, Kudish K, Fielin M, et coll. Preliminary results: surveillance for Guillain-Barre syndrome after receipt of influenza $A$ (H1N1) 2009 monovalent vaccine - United States, 2009-2010. MMWR. 2010;59:657-61.

(79) Sivadon-Tardy V, Orlikowski D, Porcher R, et coll. Guillain-Barre syndrome and influenza virus infection. Clin Infect Dis. 2009;48(1):48-56.

(80) Stowe J, Andrews N, Wise L, et coll. Investigation of the temporal association of Guillain-Barre syndrome with influenza vaccine and influenza like illness using the United Kingdom General Practice Research Database. Am J Epidemiol. 2009;169(3):382-8.

(81) Tam CC, O’Brien SJ, Petersen I, et coll. Guillain-Barre syndrome and preceding infection with campylobacter, influenza and Epstein-Barr virus in the general practice research database. PLoS ONE. 2007;2(4):e344.

(82) Grimaldi-Bensouda L, Alperovitch A, Besson G, et coll. Guillain-Barre syndrome, influenza-like illnesses, and influenza vaccination during seasons with and without circulating A/H1N1 viruses. Am J Epidemiol. $2011 ; 174(3): 326-35$.

(83) Andrews N, Stowe J, Al-Shahi Salman R, et coll. Guillain-Barre syndrome and H1N1 (2009) pandemic influenza vaccination using an ASO3 adjuvanted vaccine in the United Kingdom: self-controlled case series. Vaccine. 2011;29(45):7878-82.

(84) Simonsen L, Fukuda K, Schonberger LB, et coll. The impact of influenza epidemics on hospitalizations. J Infect Dis. 2000;181(3):831-7.

(85) McNeil S, Halperin B, MacDonald N. Influenza in pregnancy: the case for prevention. Adv Exp Med Biol. 2009;634:161-83.

(86) Mak TK, Mangtani P, Leese J, et coll. Influenza vaccination in pregnancy: current evidence and selected national policies. Lancet Infect Dis. 2008;8(1):44-52. 
(87) Rasmussen SA, Jamieson DJ, Bresee JS. Pandemic influenza and pregnant women. Emerg Infect Dis. 2008;14(1):95-100.

(88) Siston AM, Rasmussen SA, Honein MA, et coll. Pandemic 2009 influenza A (H1N1) virus illness among pregnant women in the United States. JAMA. 2010;303(15):1517-25.

(89) Louie JK. Acosta M. Jamieson DJ, et coll. California Pandemic (H1N1) Working Group. Severe 2009 H1N1 influenza in pregnant and postpartum women in California. N Engl J Med. 2010;362(1):27-35.

(90) Goldenberg R, Culhane J, lams J, et coll. Epidemiology and causes of preterm birth. Lancet. 2008;371(9606):75-84.

(91) McNeil SA, Dodds LA, Fell DB, et coll. Effect of respiratory hospitalization during pregnancy on infant outcomes. Am J Obstet Gynecol. 2011;204 (6 Suppl 1):S54-7.

(92) Pierce M, Kurinczuk J, Spark P, et coll. Perinatal outcomes after maternal 2009/H1N1 infection: national cohort study. BMJ.British medical journal. 2011;342:d3214-.

(93) Centers for Disease Control and Prevention (CDC). Maternal and infant outcomes among severely ill pregnant and postpartum women with 2009 pandemic influenza A (H1N1)-United States, April 2009-August 2010. MMWR - Morbidity \& Mortality Weekly Report. 2011;60(35):1193-6.

(94) France EK, SmithRay R, McClure D, et coll. Impact of Maternal Influenza Vaccination During Pregnancy on the Incidence of Acute Respiratory IIIness Visits Among Infants. Arch Pediatr Adolesc Med. 2006;160(12):1277-83.

(95) Zaman K, Roy E, Arifeen SE, et coll. Effectiveness of maternal influenza immunization in mothers and infants. N Engl J Med. 2008;359(15):1555-64.

(96) Poehling K, Szilagyi P, Staat M, et coll. Impact of maternal immunization on influenza hospitalizations in infants. Obstet Gynecol. 2011;204(6 Suppl 1):S141-8.

(97) Eick AA, Uyeki TM, M.P.P., Klimov A, et coll. Maternal Influenza Vaccination and Effect on Influenza Virus Infection in Young Infants. Arch Pediatr Adolesc Med. 2011;165(2):104-11.
(98) Fell DB, Sprague AE, Liu N, et coll. H1N1 Influenza Vaccination During Pregnancy and Fetal and Neonatal Outcomes. Am J Public Health. 2012;102(6):e33-40.

(99) Omer S, Goodman D, Steinhoff M, et coll. Maternal influenza immunization and reduced likelihood of prematurity and small for gestational age births: a retrospective cohort study. PLoS Medicine. 2011;8(5):e1000441-.

(100) Steinhoff M, Omer S, Roy E, et coll. Neonatal outcomes after influenza immunization during pregnancy: a randomized controlled trial. Canadian Medical Association.Journal CMAJ.

2012;184(6):645-53.

(101) Dodds L, MacDonald N, Scott J, et coll. The effect of influenza vaccine in pregnancy on adverse neonatal outcomes. J Obstetr Gynecol Canada. (In press).

(102) Steinhoff MC, Omer, SB. Roy E, et coll. Influenza Immunization in Pregnancy - Antibody Responses in Mothers and Infants. N Engl J Med. 2010;362(17):1644-6.

(103) Omer SB, Bednarczyk R, Madhi SA, et coll. Benefits to mother and child of influenza vaccination during pregnancy. Hum Vaccin Immunother. 2012;8(1):130-7.

(104) Tamma PD, Ault KA, del Rio C, et coll. Safety of influenza vaccination during pregnancy. American Journal of Obstetrics \& Gynecology. 2009;201(6):547-52.

(105) MacDonald NE, Riley LE, Steinhoff MC. Influenza immunization in pregnancy. Obstet Gynecol. 2009;114(2 Pt 1):365-8.

(106) Moro PL, Broder K, Zheteyeva Y, et coll. Adverse events in pregnant women following administration of trivalent inactivated influenza vaccine and live attenuated influenza vaccine in the Vaccine Adverse Event Reporting System, 1990-2009. Am J Obstet Gynecol. 2011;204(2):146.e1-7.

(107) Agence de la santé publique du Canada. Rapport de surveillance des effets secondaires suivant l'immunisation. 2010, 27 avril

(108) European Medicines Agency. Fifteenth Pandemic Pharmacovigilance update. 8 April 2010. Immunization. 2010 Apr 27; Disponible au : http:// www.ema.europa.eu/pdfs/influenza/21323810en.pdf 
(109) Groom AV, Jim C, Laroque M, et coll. Pandemic influenza preparedness and vulnerable populations in tribal communities. Am J Public Health. 2009;99(Suppl 2):S271-8.

(110) Samet JM, Key CR, Kutvirt DM, et coll. Respiratory disease mortality in New Mexico's American Indians and Hispanics. Am J Public Health. 1980;70(5):492-7.

(111) La Ruche G, Tarantola A, Barboza P, et coll. The 2009 pandemic $\mathrm{H} 1 \mathrm{~N} 1$ influenza and indigenous populations of the Americas and the Pacific. Euro Surveillance: Bulletin Europeen sur les Maladies Transmissibles = European Communicable Disease Bulletin. 2009;14(42).

(112) Centers for Disease Control and Prevention (CDC). Deaths related to 2009 pandemic influenza A (H1N1) among American Indian/Alaska Natives - 12 states, 2009. MMWR Morb Mortal Wkly Rep. 2009;58(48):1341-4.

(113) International Center for Education Statistics. Individuals, families and chidlren in poverty. In: Status and trends in the education of American Indians and Alaska Natives. 2008; Available at: http://nces.ed.gov/ pubs2008/nativetrends/ind_1_6.asp.

(114) Canada. Royal Commission on Aboriginal peoples: People to people, nation to nation. Highlights from the report of the Royal Commission on Aboriginal peoples. 1996; Available at: http://www.ainc-inac.gc. ca/ap/pubs/rpt/rpt-eng.asp

(115) Clark M, Riben P, Nowgesic E. The association of housing density, isolation and tuberculosis in Canadian First Nations communities. Int J Epidemiol. 2002;31(5):940-5.

(116) Zarychanski R, Stuart TL, Kumar A, et coll. Correlates of severe disease in patients with 2009 pandemic influenza (H1N1) virus infection. CMAJ. 2010;182(3):257-64.

(117) Larcombe L, Rempel JD, Dembinski I, et coll. Differential cytokine genotype frequencies among Canadian Aboriginal and Caucasian populations. Genes Immun. 2005;6(2):140-4.

(118) Carman WF, Elder AG, Wallace LA, et coll. Effects of influenza vaccination of health-care workers on mortality of elderly people in long-term care: a randomised controlled trial. Lancet. 2000;355(9198):93-7.
(119) Hayward AC, Harling R, Wetten S, et coll. Effectiveness of an influenza vaccine programme for care home staff to prevent death, morbidity, and health service use among residents: cluster randomised controlled trial. BMJ.

2006;333(7581):1241.

(120) Pearson ML. Bridges CB. Harper SA. Healthcare Infection Control Practices Advisory Committee (HICPAC). Advisory Committee on Immunization Practices (ACIP). Influenza vaccination of health-care personnel: recommendations of the Healthcare Infection Control Practices Advisory Committee (HICPAC) and the Advisory Committee on Immunization Practices (ACIP). MMWR Recomm Rep. 2006;55(RR-2):1-16.

(121) Potter J, Stott DJ, Roberts MA, et coll. Influenza vaccination of health care workers in long-term-care hospitals reduces the mortality of elderly patients. J Infect Dis. 1997;175(1):1-6.

(122) Lemaitre $M$, Meret $T$, Rothan-Tondeur $M$, et coll. Effect of influenza vaccination of nursing home staff on mortality of residents: a cluster-randomized trial. J Am Geriatr Soc. 2009;57(9):1580-6.

(123) Saxen H, Virtanen M. Randomized, placebocontrolled double blind study on the efficacy of influenza immunization on absenteeism of health care workers. Pediatr Infect Dis J. 1999;18(9):779-83.

(124) Wilde JA, McMillan JA, Serwint J, et coll. Effectiveness of influenza vaccine in health care professionals: a randomized trial. JAMA. 1999;281(10):908-13.

(125) Shugarman LR, Hales C, Setodji CM, et coll. The influence of staff and resident immunization rates on influenza-like illness outbreaks in nursing homes. J Am Med Dir Assoc. 2006;7(9):562-7.

(126) Bridges CB, Lim W, Hu-Primmer J, et coll. Risk of influenza $A$ (H5N1) infection among poultry workers, Hong Kong, 1997-1998. J Infect Dis. 2002;185(8):1005-10.

(127) Puzelli S, Di Trani L, Fabiani C, et coll. Serological analysis of serum samples from humans exposed to avian H7 influenza viruses in Italy between 1999 and 2003. J Infect Dis. 2005;192(8):1318-22. 
(128) Tweed SA, Skowronski DM, David ST, et coll. Human illness from avian influenza H7N3, British Columbia. Emerg Infect Dis. 2004;10(12):2196-9.

(129) Skowronski DM, Li Y, Tweed SA, et coll. Protective measures and human antibody response during an avian influenza H7N3 outbreak in poultry in British Columbia, Canada. CMAJ. 2007;176(1):47-53.

(130) Department of Health UK. Flu vaccination for poultry workers. 2007; Disponible au :http://www.dh.gov.uk/ en/Publicationsandstatistics/Publications/ PublicationsPolicyAndGuidance/DH_063041

(131) Gray GC, Trampel DW, Roth JA. Pandemic influenza planning: shouldn't swine and poultry workers be included?. Vaccine. 2007;25(22):4376-81.
(132) Comité consultatif de la médecine tropicale et de la médecine des voyages (CMTMV), Comité consultatif national sur l'immunisation (CCNI). Déclaration sur les voyages, la grippe et la prévention. RMTC 2005;31(ACS-2):1-8.

(133) Van Damme P, Arnou R, Kafeja F, et coll. Evaluation of non-inferiority of intradermal versus adjuvanted seasonal influenza vaccine using two serological techniques: a randomised comparative study. BMC Infect Dis. 2010;10:134.

(134) Thomas RE, Jefferson T, Lasserson TJ. Influenza vaccination for healthcare workers who work with the elderly. Cochrane Database Syst Rev. 2010(2):005187. 